\title{
Adenosine A2a Receptors Improve Hypoxic Pulmonary Arterial Hypertension Via Mitochondrial ATP-sensitive Potassium Channels
}

\section{Type}

Research paper

\section{Keywords}

proliferation, apoptosis, pulmonary vascular remodeling, A2a receptor, mitochondrial ATP-sensitive potassium channels

\begin{abstract}
Introduction

This study is aimed to explore the effects of Adenosine A2a receptors (A2aR) on hypoxia-induced pulmonary hypertension (HPH) via mitochondrial ATP-sensitive potassium channels (MitoKATP) in vivo and in vitro.

\section{Material and methods}

Using wild-type (WT) and A2aR-deficient (A2aR-/-) mice; hypoxic pulmonary artery smooth muscle cells (PASMCs) were induced by a 24-hours hypoxia exposure. Mice and PASMCs were treated with the A2aR agonist CGS21680, MitoKATP blocker 5-hydroxydecanoic acid sodium salt (5HD), or MitoKATP agonist diazoxide. Mitochondrial morphology was observed by electron microscopy. The mitochondrial membrane potential $(\Delta \psi \mathrm{m})$; invasive hemodynamic parameters; right ventricular (RV) hypertrophy index; pulmonary arterial remodeling index; proliferative and apoptotic indexes; protein expression levels of A2aR, Bax, $\mathrm{Bcl}-2$, and Caspase-9; and release of cytochrome $\mathrm{C}$ from the mitochondria to the cytoplasm were measured.
\end{abstract}

\section{Results}

In vitro, hypoxia induced the opening of MitoKATP. The up-regulation of A2aR reduced the opening of MitoKATP, and the blocking of MitoKATP or activating A2aR promoted mitochondria-dependent apoptosis of PASMCs. In vivo, compared with WT mice, A2aR-/- mice displayed increased RV systolic pressure, RV hypertrophy index, and pulmonary arterial remodeling index. The expression levels of Bax, cytochrome C, and Caspase-9 were higher and Bcl-2 expression was lower in A2aR-/mice than in WT mice. CGS21680 could reverse hypoxia-induced hemodynamic changes, RV hypertrophy, and pulmonary arterial remodeling as well as abnormal proliferation and apoptosis resistance in WT mice with pulmonary hypertension $(\mathrm{PH})$.

\section{Conclusions}

A2aR induced the mitochondrial-dependent apoptosis pathway and inhibited PASMC proliferation by blocking MitoKATP, thereby inhibiting pulmonary vascular structural remodeling and reducing $\mathrm{PH}$. 
1 Adenosine $\mathbf{A}_{2 a}$ Receptors Improve Hypoxic Pulmonary Arterial Hypertension Via

2 Mitochondrial ATP-sensitive Potassium Channels

3

4 Running Title: The mechanism of A2aR improving HPH

5

6 Keywords: pulmonary vascular remodeling; $\mathrm{A}_{2 \mathrm{a}}$ receptor; mitochondrial ATP-sensitive potassium

7 channels; apoptosis; proliferation 


\section{Abstract}

Aim: This study is aimed to explore the effects of Adenosine $A_{2 a}$ receptors $\left(A_{2 a} R\right)$ on hypoxia-induced pulmonary hypertension (HPH) via mitochondrial ATP-sensitive potassium channels (MitoK $\left.\mathrm{ATP}_{\mathrm{AT}}\right)$ in vivo and in vitro.

Main Methods: Using wild-type (WT) and $\mathrm{A}_{2 \mathrm{a}} \mathrm{R}$-deficient $\left(\mathrm{A}_{2 \mathrm{a}} \mathrm{R}^{-/-}\right)$mice; hypoxic pulmonary artery smooth muscle cells (PASMCs) were induced by a 24-hours hypoxia exposure. Mice and PASMCs were treated with the $\mathrm{A}_{2 \mathrm{a}} \mathrm{R}$ agonist CGS21680, MitoK $\mathrm{K}_{\text {ATP }}$ blocker 5-hydroxydecanoic acid sodium salt (5HD), or MitoK ${ }_{\text {ATP }}$ agonist diazoxide. Mitochondrial morphology was observed by electron microscopy. The mitochondrial membrane potential $(\Delta \psi \mathrm{m})$; invasive hemodynamic parameters; right ventricular (RV) hypertrophy index; pulmonary arterial remodeling index; proliferative and apoptotic indexes; protein expression levels of $\mathrm{A}_{2 \mathrm{a}} \mathrm{R}, \mathrm{Bax}, \mathrm{Bcl}-2$, and Caspase-9; and release of cytochrome $\mathrm{C}$ from the mitochondria to the cytoplasm were measured.

Key findings: In vitro, hypoxia induced the opening of MitoK $\mathrm{K}_{\text {ATP. The }}$ up-regulation of $\mathrm{A}_{2 \mathrm{a}} \mathrm{R}$ reduced the opening of MitoK $\mathrm{ATP}_{\mathrm{ATP}}$, and the blocking of MitoK $\mathrm{ATP}_{\mathrm{AT}}$ or activating $\mathrm{A}_{2 \mathrm{a}} \mathrm{R}$ promoted mitochondria-dependent apoptosis of PASMCs. In vivo, compared with WT mice, $\mathrm{A}_{2 \mathrm{a}} \mathrm{R}^{-1-}$ mice displayed increased RV systolic pressure, RV hypertrophy index, and pulmonary arterial remodeling index. The expression levels of Bax, cytochrome C, and Caspase-9 were higher and Bcl-2 expression was lower in $\mathrm{A}_{2 \mathrm{a}} \mathrm{R}^{-/-}$mice than in WT mice. CGS21680 could reverse hypoxia-induced hemodynamic changes, RV hypertrophy, and pulmonary arterial remodeling as well as abnormal proliferation and apoptosis resistance in WT mice with pulmonary hypertension $(\mathrm{PH})$.

Significance: $\mathrm{A}_{2 \mathrm{a}} \mathrm{R}$ induced the mitochondrial-dependent apoptosis pathway and inhibited PASMC proliferation by blocking MitoK $_{\text {ATP }}$, thereby inhibiting pulmonary vascular structural remodeling and reducing $\mathrm{PH}$.

\section{Introduction}

Pulmonary hypertension $(\mathrm{PH})$ is a potentially fatal disease characterized by excessive pulmonary 
vasoconstriction, vascular remodeling and pulmonary arteriole occlusion. These pathological symptoms cause a continuous increase in pulmonary artery pressure, which aggravates the right ventricular (RV) afterload, leading to RV failure and even death [1]. The median survival rate of patients treated with traditional methods is only 2.8 years, and the 1-, 3-, and 5-year survival rates are $68 \%, 48 \%$, and $34 \%$, respectively; therefore, the prognosis remains very poor $[2,3,4]$.

Multiple cell and molecular signaling pathways are involved in the pathological process of pulmonary vascular remodeling [5,6]. At present, the complex pathogenesis of $\mathrm{PH}$ is not fully understood; however, an increasing number of studies have confirmed that pulmonary vascular remodeling plays an important role in the development of $\mathrm{PH}$ [7-10].

Adenosine is an endogenous mediator that is often used as a cytoprotective modulator for stress responses and has strong vasodilator and anti-inflammatory effects. Adenosine signaling has an important regulatory role in various physiological and pathological conditions via the four subtypes of $G$ protein-coupled receptors $\left(\mathrm{A}_{1}, \mathrm{~A}_{2 \mathrm{a}}, \mathrm{A}_{2 \mathrm{~b}}\right.$, and $\left.\mathrm{A}_{3}\right)$, which are expressed in the lung [11]. Adenosine $A_{2 a}$ receptor $\left(A_{2 a} R\right)$ is a highly expressed receptor with complex functions [12].

Adenosine activates $A_{2 a} \mathrm{R}$ to cause vasodilation, thereby reducing systemic circulation and pulmonary circulation pressure [13]. Xu [14] found that $\mathrm{A}_{2 \mathrm{a}} \mathrm{R}$-deficient $\left(\mathrm{A}_{2 \mathrm{a}} \mathrm{R}^{-I_{-}}\right)$mice exhibit pulmonary arterial pressure elevation, pulmonary vascular remodeling, and excessive proliferation of pulmonary artery smooth muscle cells (PASMCs) compared with wild-type (WT) mice. Moreover, our previous study showed that activation of A2aR could relieve hypoxia-induced pulmonary hypertension [15]. However, the specific mechanism remains to be elucidated.

ATP-sensitive potassium channels $\left(\mathrm{K}_{\text {ATP }}\right)$ are ionic channels that influence the excitability and 
metabolism of cells and thereby affect function [16]. The mitochondrial apoptotic pathway is an important signal transduction pathway in apoptosis. Mitochondrial membrane potential is associated with the integrity of mitochondrial function; the mitochondrial ATP-sensitive potassium channel (MitoK $\mathrm{K}_{\mathrm{ATP}}$ ), a $\mathrm{K}_{\mathrm{ATP}}$ channel in the mitochondrial membrane of PASMCs, is closely associated with the maintenance of mitochondrial membrane potential [17]. Hu [18] found that hypoxia can activate the activity of MitoK $\mathrm{ATP}_{\mathrm{AT}}$ in PASMCs, promoting their opening and partial depolarization of the mitochondrial membrane potential $(\Delta \psi \mathrm{m})$, subsequent inhibition of the release of cytochrome $\mathrm{C}(\mathrm{Cyt} \mathrm{C})$, and ultimately promoting proliferation and inhibition of apoptosis in smooth muscle cells. The opening of MitoKATP channel can promote hypoxia-induced proliferation of human PASMCs [19]. These findings suggest that MitoK $\mathrm{ATP}_{\mathrm{AP}}$ is associated with the development of $\mathrm{PH}$.

Additionally, adenosine can stimulate the activity of $\mathrm{K}_{\mathrm{ATP}}$ and calcium-activated potassium channels by activating the $A_{2 a}$ receptor, thereby expanding the coronary vessels [20]. We speculated that $A_{2 a} R$ could also affect pulmonary circulation via MitoK $\mathrm{ATP}_{\mathrm{AP}}$, ultimately reducing pulmonary vascular remodeling and preventing $\mathrm{PH}$. To evaluate this hypothesis, the effects of $\mathrm{A}_{2 \mathrm{a}} \mathrm{R}$ on $\mathrm{HPH}$ via $\mathrm{MitoK}_{\mathrm{ATP}}$ were determined in vivo and in vitro.

\section{Materials and methods}

\section{Reagents}

The $\mathrm{A}_{2 \mathrm{a}} \mathrm{R}$ agonist CGS21680, MitoK $\mathrm{ATP}_{\text {AT }}$ blocker 5-hydroxydecanoic acid sodium salt (5HD), and MitoK $_{\text {ATP }}$ agonist diazoxide were obtained from Sigma-Aldrich (St. Louis, MO, USA). Dulbecco's modified Eagle medium (high glucose), streptomycin, penicillin G, and fetal bovine serum were 
obtained from Gibco BRL (Gaithersburg, MD, USA). Rabbit antibodies against Bax, Caspase-9, proliferating cell nuclear antigen (PCNA), and $\mathrm{A}_{2 \mathrm{a}} \mathrm{R}$ were purchased from Abcam (Cambridge, UK). Rabbit antibodies against Bcl-2, Cyt C, COX IV, and GAPDH were purchased from Cell Signaling Technology (Beverly, MA, USA). Goat anti-rabbit IgG conjugated to horseradish peroxidase was provided by Beyotime (Haimen, China). SuperSignal ${ }^{\circledR}$ West Femto Maximum Sensitivity Substrate, a BCA Protein Assay Kit, and a Mitochondria Isolation Kit for Tissue were purchased from Thermo Fisher (Madison, WI, USA). A DAB Kit and Polink-2 Plus Polymer HRP Detection System were purchased from ZSGB Biotech (Beijing, China). The in situ Cell Death Detection Kit was purchased from Roche (Indianapolis, IN, USA).

\section{Animal models}

Fifty 12 - to 14 -week-old male BALB/c mice weighing approximately $20-25 \mathrm{~g}$ were purchased from Slac Experimental Animal Technology (Shanghai, CHN), and forty 12- to 14-week-old, male $\mathrm{A}_{2 \mathrm{a}} \mathrm{R}^{-/-}$BALB/c mice weighing approximately $20-25 \mathrm{~g}$ were purchased from Jackson Laboratory (Bar Harbor, ME, USA). All animals were fed in a specific pathogen-free animal laboratory, and the laboratory and experimental protocols were reviewed and approved by Wenzhou Medical University Animal Experiment Center. In the laboratory, the mice were maintained under a 12-hour day-night cycle at $20-24{ }^{\circ} \mathrm{C}$ and were allowed free access to sufficient food and water.

Fifty WT mice were randomly divided into the following five groups (10 mice per group): a WT normal control group (N, saline-treated), a WT hypoxia group (H, saline-treated), a WT hypoxia plus 5HD group (H5HD, $10 \mathrm{mg} / \mathrm{kg}$ ), a WT hypoxia plus diazoxide group (HDia, $7 \mathrm{mg} / \mathrm{kg}$ ), and a WT hypoxia plus CGS21680 group (HCGS, $0.2 \mathrm{mg} / \mathrm{kg}$ ). Forty $\mathrm{A}_{2 \mathrm{a}} \mathrm{R}^{-/}$mice were randomly 
divided into the following four groups (10 mice per group): an $\mathrm{A}_{2 \mathrm{a}} \mathrm{R}^{-1-}$ normoxia group ( $\mathrm{K}$, saline-treated), $\mathrm{A}_{2 \mathrm{a}} \mathrm{R}^{-/-}$hypoxia group (HK, saline-treated), $\mathrm{A}_{2 \mathrm{a}} \mathrm{R}^{-/-}$hypoxia plus 5HD group (HK5HD, $10 \mathrm{mg} / \mathrm{kg}$ ), and $\mathrm{A}_{2 \mathrm{a}} \mathrm{R}^{-/-}$hypoxia plus diazoxide group (HKDia, $7 \mathrm{mg} / \mathrm{kg}$ ). Control mice in groups $\mathrm{N}$ and $\mathrm{K}$ were exposed to room air while the hypoxia groups were exposed to $9 \%-11 \%$ $\mathrm{O}_{2}$. HPH mouse models were established over a 4-week period by placing mice in the hypoxia groups in a closed chamber ( 8 hours per day) and by monitoring and automatically controlling the $\mathrm{O}_{2}$ concentration using a detector as previously described [15].

\section{Cell culture and treatment}

PASMCs were cultured in Dulbecco's modified Eagle medium supplemented with $100-\mu \mathrm{g} / \mathrm{mL}$ streptomycin, 100-IU/mL penicillin, and $10 \%$ fetal bovine serum. After reaching $80 \%$ confluence, cells were treated with $0.25 \%$ trypsin-EDTA for further passaging. PASMCs were used at fifth passage. The cultured cells were confirmed to be PASMCs by immunofluorescence. For further in vitro study, PASMCs were divided into the following groups: a normoxia group $(\mathrm{N})$, a hypoxia group $(\mathrm{H})$, a hypoxia plus $5 \mathrm{HD}$ group $(\mathrm{H} 5 \mathrm{HD}, 500 \mu \mathrm{mol} / \mathrm{L})$, a hypoxia plus diazoxide group (HDia, $100 \mu \mathrm{mol} / \mathrm{L}$ ), a hypoxia plus $\mathrm{A}_{2 \mathrm{a}} \mathrm{R}$-knockdown group (HK), and a hypoxia plus CGS21680 group (HCGS, $2 \mu \mathrm{mol} / \mathrm{L}$ ). The $\mathrm{A}_{2 \mathrm{a}} \mathrm{R}$ gene knockdown depended on transfection of effective small interfering RNA (siRNA) synthesized by Genechem (Shanghai, China). Cells were transfected with siRNAs according to the manufacturer's protocol, and the validity of knockdown was confirmed. The normoxia group was cultured in a normal incubator $\left(37^{\circ} \mathrm{C}, 21 \% \mathrm{O}_{2}, 5 \% \mathrm{CO}_{2}\right.$, and $\left.74 \% \mathrm{~N}_{2}\right)$ for $24 \mathrm{~h}$, whereas the hypoxia groups were kept in a hypoxia incubator $\left(37{ }^{\circ} \mathrm{C}, 5 \% \mathrm{O}_{2}\right.$, $5 \% \mathrm{CO}_{2}$, and $90 \% \mathrm{~N}_{2}$ ) for $24 \mathrm{~h}$. 
118

119

120

121

122

123

124

125

126

127

128

129

130

131

132

133

134

135

136

137

138

Measurements of hemodynamic parameters and RV hypertrophy

At the end of the hypoxia exposure period, the RV systolic pressure (RVSP) and the mean carotid arterial pressure (mCAP) were measured using the method described by Huang et al. [15]. The mice were anesthetized with $20 \%$ urethane $(1 \mathrm{~mL} / 100 \mathrm{~g})$ and supine fixed, and the right external jugular vein and left carotid artery were separated. Two home-made polyethylene catheters (outer diameter: $0.9 \mathrm{~mm}$, inner diameter: $0.5 \mathrm{~mm}$ ) connected to pressure transducers and prefilled with heparin were inserted into the RV and left carotid artery, and RVSP and mCAP were measured and analyzed using a PowerLab 8/35 Multi-channel Biological Signal Recording System (AD Instruments, Colorado Springs, Australia). After sacrificing mice by exsanguination, their hearts were removed and divided into the RV, left ventricle (LV), and septum (S), and each section was weighed. The weight ratios $\mathrm{RV} /(\mathrm{LV}+\mathrm{S})$ and $\mathrm{RV} /$ body weight $(\mathrm{BW})$ were calculated as indexes of RV hypertrophy. Additionally, a portion of the lung tissue was homogenized to detect the expression of $\mathrm{A}_{2 \mathrm{a}} \mathrm{R}$ in each group by western blotting.

\section{Measurement of pulmonary arterial remodeling}

The lung tissue was dissected and cut into several parts. The upper lobe of the right lung was promptly fixed in $4 \%$ paraformaldehyde, conventionally dehydrated, paraffin-embedded, serially sectioned at a thickness of $4 \mu \mathrm{m}$, and then stained with hematoxylin-eosin (HE). After HE staining, the structural remodeling of the pulmonary arteries was observed by microscopy. Pulmonary arteries (external diameters, 25-100 $\mu \mathrm{m}$ ) were randomly selected and analyzed using Image-Pro Plus 6.0 (Media Cybernetics, Rockville, MD, USA). The ratios (expressed as percentages) of the pulmonary artery wall area to the total area (WA/TA\%) and the wall thickness to the total 
139

140

141

142

143

144

145

146

147

148

149

150

151

152

153

thickness (WT/TT\%) were calculated to evaluate pulmonary arterial remodeling as previously described [15].

\section{Ultrastructural examination of pulmonary arteries}

Tissue samples of approximately $1 \times 1 \times 3 \mathrm{~mm}^{3}$ were taken from the left lung near the hilum. The tissues were fixed with $2.5 \%$ glutaraldehyde and $1 \%$ osmic acid, stained with $1 \%$ uranium acetate, dehydrated with acetone, and embedded in epoxy resin. Subsequently, the fixed tissues were sectioned (semithin and ultrathin sections), and the ultrathin sections were examined using an H-7500 transmission electron microscope (Hitachi, Tokyo, Japan).

\section{Detection of mitochondrial membrane potential}

Rhodamine-123 can cross the mitochondrial membrane in living cells, and its fluorescence intensity is linearly correlated with $\Delta \psi \mathrm{m}$. PASMCs were incubated with rhodamine-123 (10 mg/L) for $30 \mathrm{~min}$ at $37{ }^{\circ} \mathrm{C}$. The fluorescence intensity was detected by laser confocal microscopy (Olympus FV1000, Tokyo, Japan) and analyzed using Image-Pro Plus 6.0. The optical densities of the respective images were measured and expressed as the corrected average optical density.

\section{Detection of proliferation}

PCNA is usually expressed in the DNA synthesis phase of the cell cycle. To detect PCNA expression levels, $10-\mu \mathrm{m}$-thick paraffin sections of lung tissues were dehydrated with ethanol, heat induced for antigen retrieval, blocked with normal goat serum, and incubated with anti-PCNA antibody (1:100) overnight at $4{ }^{\circ} \mathrm{C}$. Subsequently, the sections were incubated with goat anti-rabbit IgG conjugated to horseradish peroxidase (1:100). Diaminobenzidine was used as the chromogen, and hematoxylin was used for counterstaining. The sections were then observed under 
a microscope (ICC50W0859, Leica, Germany), and the percentages of positive cells were assessed in five randomly selected pulmonary arteries (external diameters of $100 \mu \mathrm{m}$ ).

\section{Detection of apoptosis}

The terminal deoxyribonucleotide transferase mediated dUTP nick-labeling (TUNEL) assay (using the in situ Cell Death Detection Kit, POD) was used to detect apoptosis. After tissue sections were dewaxed and rehydrated with xylene and ethanol, they were treated with a $3 \%$ hydrogen peroxide solution to block endogenous peroxidase. After cell drilling with Triton-X100, every tissue section was incubated with the TUNEL reaction mixture and transforming agent POD.

\section{Western blotting analyses}

Lung tissues were homogenized in cold RIPA lysis buffer using an automatic homogenizer (FastPrep-24 5G, MP Biomedicals, Irvine, CA, USA), then lysed using an ultrasonic disruptor. The supernatants were collected after the homogenates were centrifuged $\left(12,000 \mathrm{rpm}, 4^{\circ} \mathrm{C}\right)$ for $30 \mathrm{~min}$. PASMCs were lysed with cold RIPA lysis buffer containing phenylmethylsulfonyl fluoride. The supernatants were collected after the lysates were centrifuged $\left(12,000 \mathrm{rpm}, 4{ }^{\circ} \mathrm{C}\right)$ for $30 \mathrm{~min}$. Protein concentrations were determined using a Pierce BCA Protein Assay Kit (Thermo Fisher, Waltham, MA, USA). Equal amounts of proteins were separated by SDS-PAGE; transferred to PVDF membranes (Millipore, Burlington, MA, USA); blocked with 5\% skim milk; and incubated with specific primary antibodies against A2aR (1:1,000), Bax (1:1,000), Bcl-2 (1:1,000), Caspase-9 $(1: 1,000), \beta$-tubulin $(1: 1,000)$, and GAPDH $(1: 1,000)$ overnight at $4^{\circ} \mathrm{C}$ before being incubated with goat anti-rabbit IgG conjugated to horseradish peroxidase $(1: 10,000)$. To detect Cyt 
181

$\mathrm{C}$ release, mitochondrial and cytosol pellets were isolated using a Mitochondria Isolation Kit for Tissue and immunoblotted with antibodies against Cyt C $(1: 1,000)$, with COX IV serving as the mitochondrial marker and GAPDH as the cytosolic marker. After the pellets were triple washed with phosphate-buffered saline, the immunoreactive bands were visualized using SuperSignal chemiluminescence substrates (Thermo Fisher) and were analyzed using Image Lab 5.1 (Bio-Rad Laboratories, Hercules, CA, USA).

\section{Statistical analysis}

All statistical analyses were performed using SPSS 20.0 (IBM, Somers, NY, USA). All results are expressed as mean \pm standard deviation (SD) and were tested for normality. Comparisons between two groups were performed using Student's $t$-tests, and comparisons among multiple groups were performed using one-way analysis of variance with the LSD test (equal variances assumed). A p-value of $<0.05$ was considered statistically significant.

\section{Results}

\section{$A_{2 a} R$ reversed the hypoxia-induced opening of MitoK ${ }_{A T P}$ in PASMCs}

To assess whether $\mathrm{A}_{2 \mathrm{a}} \mathrm{R}$ reverses the hypoxia-induced opening of $\mathrm{MitoK}_{\mathrm{ATP}}$ in PASMCs, we first established an $\mathrm{A}_{2 \mathrm{a}} \mathrm{R}$-down-regulated PASMC model by siRNA and examined the knockdown efficiency of siRNA by western blotting. As shown in Fig. 1a, siRNA-A ${ }_{2 \mathrm{a}} \mathrm{R}$ significantly reduced the expression of $\mathrm{A}_{2 \mathrm{a}} \mathrm{R}$ protein in PASMCs by $40 \%(\mathrm{p}<0.05)$. Then, we used the fluorescence intensity of Rhodamine 123 to indicate the opening level of MitoK $\mathrm{ATP}_{\mathrm{P}}$ in PASMCs of different groups. As shown in Fig. $1 \mathrm{~b}$ and $\mathrm{c}$, compared with that in the $\mathrm{N}$ group, the rhodamine-123 fluorescence intensity in the $\mathrm{H}$ group was significantly higher $(\mathrm{p}<0.01)$, which indicated that 
hypoxia promoted the opening of MitoK $_{\mathrm{ATP}}$ in PASMCs. Interestingly, the rhodamine-123 fluorescence intensity ratio was significantly decreased post CGS21680 treatment $(p<0.05)$. In contrast, when the $A_{2 a} R$ gene was knocked down, the fluorescence intensity ratio was further enhanced in the HK group $(p<0.01)$. Ultimately, these results indicate that $A_{2 a} R$ reversed the hypoxia-induced opening of MitoK $\mathrm{ATP}_{\mathrm{A}}$ in PASMCs.

\section{$A_{2 a} R$ alleviated hypoxia-induced hemodynamic changes by blocking MitoK $K_{A T P}$}

To determine the protective effects of $\mathrm{A}_{2 \mathrm{a}} \mathrm{R}$ in $\mathrm{HPH}, \mathrm{A}_{2 \mathrm{a}} \mathrm{R}$ protein expression in lung homogenates was first examined by western blotting. In vivo, as shown in Fig. $2 \mathrm{a}, \mathrm{A}_{2 \mathrm{a}} \mathrm{R}$ was not expressed in the $\mathrm{A}_{2 \mathrm{a}} \mathrm{R}^{-/}$groups. $\mathrm{A}_{2 \mathrm{a}} \mathrm{R}$ expression increased in hypoxia-exposed WT mice than that in normoxic mice $(\mathrm{p}<0.05)$. Moreover, CGS21680 treatment significantly enhanced $A_{2 a} R$ expression compared with hypoxia treatment $(\mathrm{p}<0.05)$. Then, RVSP in each group was recorded to reflect the pulmonary arterial pressure after 4 weeks of treatment. As shown in Fig. 2b and d, RVSP was significantly higher in groups exposed to hypoxia (groups $\mathrm{H}$ and $\mathrm{HK}$ ) than in groups exposed to normoxia (groups $\mathrm{N}$ and $\mathrm{K})(\mathrm{p}<0.01$ ), and RVSP in the HK group was higher than in the $\mathrm{H}$ group ( $\mathrm{p}<0.05)$. The hypoxia-induced increase in RVSP was inhibited by CGS21680 treatment $(\mathrm{p}<$ 0.05). These results indicate that the hypoxia-induced increase in RVSP is alleviated by an increase $\mathrm{A}_{2 \mathrm{a}} \mathrm{R}$ and exacerbated by its decrease. The hypoxia-induced increase in RVSP was reduced by treatment with 5HD $(\mathrm{p}<0.05)$, but it was further increased by treatment with diazoxide in both WT and $\mathrm{A}_{2 \mathrm{a}} \mathrm{R}^{-/-}$groups $(\mathrm{p}<0.05)$. Accordingly, hypoxia-induced increases in RVSP are alleviated by blocking MitoK $_{\text {ATP }}$ and exacerbated by promoting its opening. Furthermore, RVSP in the HK5HD group was significantly higher than in the H5HD group ( $p<$ 
224

with previous research that found that $\mathrm{A}_{2 \mathrm{a}} \mathrm{R}$ could reverse the hypoxia-induced opening of MitoK $\mathrm{ATP}_{\text {AT }}$ PASMCs, these results indicate that $\mathrm{A}_{2 \mathrm{a}} \mathrm{R}$ alleviated hypoxia-induced hemodynamic

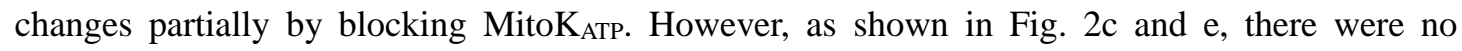
significant differences in mCAP among these nine groups.

\section{$A_{2 a} R$ alleviated hypoxia-induced $R V$ hypertrophy and pulmonary arterial remodeling by}

\section{blocking MitoK $\mathrm{K}_{\mathrm{ATP}}$}

To evaluate the degree of RV hypertrophy, we measured the $\mathrm{RV} /(\mathrm{LV}+\mathrm{S})$ and $\mathrm{RV} / \mathrm{BW}$ ratios of mice after hypoxia exposure (4 weeks, 8hours per day). As shown in Fig. 3a and b, both these ratios were significantly higher in $\mathrm{WT}$ and $\mathrm{A}_{2 \mathrm{a}} \mathrm{R}^{-/-}$mice exposed to hypoxia than in those exposed to normoxia ( $\mathrm{p}<0.01)$. Treatment with CGS21680 reduced the RV/(LV+S) $(\mathrm{p}<0.05)$ and $\mathrm{RV} / \mathrm{BW}$ ratios $(\mathrm{p}<0.05)$; the ratios in the HK group were higher than those in the $\mathrm{H}$ group $(\mathrm{p}<$ 0.05). These results demonstrate that hypoxia-induced RV hypertrophy was alleviated by an increase in $\mathrm{A}_{2 \mathrm{a}} \mathrm{R}$ and exacerbated by its decrease. Repeated administration of 5HD also reduced the $\mathrm{RV} /(\mathrm{LV}+\mathrm{S}) \quad(\mathrm{p}<0.05)$ and $\mathrm{RV} / \mathrm{BW}$ ratios $(\mathrm{p}<0.05)$ in WT mice while repeated administration of diazoxide led to the opposite effects $(\mathrm{p}<0.05)$. These results show that hypoxia-induced RV hypertrophy is alleviated by blocking MitoK $\mathrm{KTP}_{\mathrm{AP}}$ and aggravated by promoting its opening. Furthermore, the $\mathrm{RV} /(\mathrm{LV}+\mathrm{S})(\mathrm{p}<0.05)$ and $\mathrm{RV} / \mathrm{BW}(\mathrm{p}<0.01)$ ratios were significantly higher in the HK5HD group than in the H5HD group, and they were also higher in the HKDia group than in the HDia group $(\mathrm{p}<0.05)$. These results indicate that $\mathrm{A}_{2 \mathrm{a}} \mathrm{R}$ alleviated hypoxia-induced RV hypertrophy partly by blocking the opening of MitoK $\mathrm{ATP}_{\text {. }}$

To investigate pulmonary arterial remodeling, we estimated the pulmonary artery wall area 
relative to the total area (WA/TA\%) and the wall thickness relative to total thickness (WT/TT\%) by HE staining. As shown in Fig. 3c-e, exposure to hypoxia for 4 weeks caused a significant increase in the wall area and thickness of the pulmonary artery in $\mathrm{WT}$ and $\mathrm{A}_{2 \mathrm{a}} \mathrm{R}^{--}$mice compared with normoxia exposure $(\mathrm{p}<0.01)$. As expected, CGS21680 exerted the strongest inhibitory effect and dramatically decreased WA/TA and WT/TT ratios $(\mathrm{p}<0.05)$. These results indicate that an increase in $\mathrm{A}_{2 \mathrm{a}} \mathrm{R}$ alleviates hypoxia-induced pulmonary arterial remodeling. Moreover, the hypoxia-induced increase in WA/TA and WT/TT ratios was aggravated by diazoxide $(\mathrm{p}<0.05)$, which was reversed by treatment with $5 \mathrm{HD}$ in both $\mathrm{WT}$ and $\mathrm{A}_{2 \mathrm{a}} \mathrm{R}^{--}$groups. These findings suggest that hypoxia-induced pulmonary arterial remodeling is alleviated by blocking the opening of MitoK $_{\text {ATP }}$ and aggravated by promotion of its opening. Additionally, WA/TA and WT/TT percentages were higher in the HK5HD $(\mathrm{p}<0.05)$ and HKDia $(\mathrm{p}<0.05)$ groups than in the H5HD and HDia groups. These results demonstrate that $\mathrm{A}_{2 \mathrm{a}} \mathrm{R}$ alleviates hypoxia-induced pulmonary arterial remodeling partially through blocking the opening of MitoK $\mathrm{ATP}_{\mathrm{AP}}$

\section{$A_{2 a} R$ alleviated hypoxia-induced excessive proliferation in PASMCs by blocking MitoK ${ }_{A T P}$}

To evaluate the proliferation of PASMCs in vivo, proliferating cell nuclear antigen (PCNA) expression was measured by immunohistochemistry. As shown in Fig. 4a and c, PCNA expression was significantly higher in the hypoxia groups than in the control groups $(\mathrm{p}<0.01)$. CGS21680 treatment significantly decreased the expression of PCNA in the HCGS group compared with that in the H group $(\mathrm{p}<0.01)$. Meanwhile, the expression of PCNA in the HK group was higher than in the $\mathrm{H}$ group $(\mathrm{p}<0.05)$. The groups treated with 5HD had observably reduced percentages of positive cells compared with that in the hypoxia groups $(\mathrm{p}<0.01)$. In contrast, repeated administration of diazoxide further increased the percentage of PCNA-positive cells $(\mathrm{p}<0.05)$. 
These results suggest hypoxia-induced excessive proliferation of PASMCs is alleviated by blocking MitoK $\mathrm{K}_{\mathrm{ATP}}$ and promoting the opening. Additionally, the percentage of PCNA-positive cells was significantly higher in the HK5HD group than in the H5HD group $(\mathrm{p}<0.01)$, and it was also higher in the HKDia group than in the HDia group $(\mathrm{p}<0.05)$.

\section{$A_{2 a} R$ decreased hypoxia-induced apoptosis resistance in PASMCs by blocking MitoK ${ }_{A T P}$}

We further investigated the effects of $\mathrm{A}_{2 \mathrm{a}} \mathrm{R}$ on cell apoptosis. In vivo, as shown in Fig. $4 \mathrm{~b}$ and $\mathrm{d}$, the percentage of apoptotic cells was significantly lower in the hypoxia groups than in the control groups $(\mathrm{p}<0.01)$. However, the decreased apoptosis index was significantly increased by treatment with CGS21680 ( $\mathrm{p}<0.01)$. Treatment with 5HD reversed chronic hypoxia-induced apoptosis resistance and increased the apoptosis index in the WT $(\mathrm{p}<0.01)$ groups. However, diazoxide treatment further decreased the percentage of apoptotic cells $(\mathrm{p}<0.05)$. Additionally, the percentage of apoptotic cells in the K5HD group was significantly lower than in the 5HD group $(\mathrm{p}<0.01)$, and the apoptosis index was lower in the KDia group than in the Dia group $(\mathrm{p}<$ $0.05)$.

Furthermore, we evaluated the expression level of apoptosis-related proteins, including Bax and Bcl-2, and calculated the ratio of Bax to Bcl-2 expression. As shown in Fig. 5a, Bax expression was significantly down-regulated in the lung tissue homogenate of the hypoxia groups compared with that in the control groups $(\mathrm{p}<0.01)$. However, treatment with CGS21680 reversed this effect ( $\mathrm{p}<0.05)$ (Fig. 5a). Additionally, the expression of Bax in the HK group was lower than in the H group ( $\mathrm{p}<0.05$ ) (Fig. 5b). These results indicate that an increase in $\mathrm{A}_{2 \mathrm{a}} \mathrm{R}$ up-regulates the expression of Bax. As shown in Fig. 5b, decreases in Bax expression induced by hypoxia were 
reversed by treatment with 5HD in the WT group $(\mathrm{p}<0.05)$. Compared with expression levels in the hypoxia groups, diazoxide further down-regulated the expression of Bax $(\mathrm{p}<0.05)($ Fig. 5c). According to these results, the expression of Bax is up-regulated by blocking MitoK $\mathrm{ATP}_{\mathrm{AT}}$ and down-regulated by promoting its opening. As shown in Fig. 5b, the effects of 5HD up-regulation of Bax was reversed in the $\mathrm{A}_{2 \mathrm{a}} \mathrm{R}^{-/-}$group, and the expression of $\mathrm{Bax}$ in the HK5HD group was lower than in the H5HD group $(\mathrm{p}<0.05)$.

The expression levels of Bcl-2 were opposite to those of Bax in each group (Fig. 5d-f). We also computed the ratio of Bax to Bcl-2 expression and found that the ratio was the same as Bax. As shown in Fig. 5g, the ratio was significantly down-regulated in the hypoxia groups compared with that in the control groups $(\mathrm{p}<0.01)$ and treatment with CGS21680 reversed this effect $(\mathrm{p}<0.01)$. Additionally, the ratio in the HK group was lower than in the $\mathrm{H}$ group $(\mathrm{p}<0.05)($ Fig. 5h-i). As shown in Fig. 5h, decreases in the ratio of Bax to Bcl-2 expression induced by hypoxia were reversed by treatment with 5HD in the WT group $(\mathrm{p}<0.01)$, and the effects of 5HD were reversed in the $\mathrm{A}_{2 \mathrm{a}} \mathrm{R}^{-/-}$group, and the ratio in the HK5HD group was lower than that in the H5HD group (p $<0.01)$. Compared with expression levels in the hypoxia groups, diazoxide further down-regulated the ratio $(\mathrm{p}<0.01)($ Fig. 5i).

\section{$A_{2 a} R$ modulated cell apoptosis via the mitochondrial-dependent apoptosis pathway}

To investigate whether $\mathrm{A}_{2 \mathrm{a}} \mathrm{R}$ modulates cell apoptosis via the mitochondrial-dependent apoptosis pathway, electron microscopy was used to observe the ultrastructure of mitochondria. In vivo, as shown in Fig. 6a, in the $\mathrm{N}$ and $\mathrm{K}$ groups, the mitochondrial bilayer membrane structure was complete, and the cristae of the mitochondria were compact. Compared with the $\mathrm{N}$ and $\mathrm{K}$ groups, 
abnormal mitochondria membrane swelling was observed in the $\mathrm{H}$ and $\mathrm{HK}$ groups (i.e., the structure of mitochondrial cristae was disordered, vacuoles appeared in few mitochondria, and some were broken). However, after treatment with CGS21680, the mitochondrial cristae became dense, the membrane was intact, and the structure tended to be normal. The destructive effects of hypoxia were reversed with 5HD treatment but aggravated by diazoxide treatment. The mitochondrial damage was more severe in the HK5HD and HKDia groups than in the H5HD and HDia groups. In groups HK5HD and HKDia, mitochondrial swelling was obvious, most of the cristae were broken and appeared blurry, and some mitochondria exhibited pyknosis.

To further clarify the relationship between $\mathrm{A}_{2 \mathrm{a}} \mathrm{R}$ and $\mathrm{MitoK}_{\mathrm{ATP}}$ in the mitochondrial-dependent apoptotic pathway, the expression levels of Cyt C and Caspase-9 were detected by western blotting. As shown in Fig. $6 \mathrm{~b}$ and d, the release of Cyt $\mathrm{C}$ from the mitochondria to the cytoplasm was significantly inhibited in the hypoxia groups compared with that in the normoxia groups (p < 0.01), which was reversed after treatment with CGS21680 ( $<<0.01)$. Meanwhile, inhibition of the pathway was reversed by treatment with 5HD in both the WT and $\mathrm{A}_{2 \mathrm{a}} \mathrm{R}^{-/-}$groups $(\mathrm{p}<0.01)$ (Fig. 6f-g). Additionally, the mice treated with diazoxide exhibited (HDia) further reductions in the release of Cyt $\mathrm{C}$ from the mitochondria to the cytoplasm than those exposed to hypoxia $(\mathrm{H})(\mathrm{p}<$ 0.05) (Fig. 6h-j). These results suggest that the mitochondrial-dependent apoptotic pathway is activated by blocking MitoK $\mathrm{ATP}_{\mathrm{AT}}$ and inhibited by promoting its opening. In addition, the effects of 5HD up-regulation of the release of $\mathrm{Cyt} \mathrm{C}$ from the mitochondria to the cytoplasm was reversed in $\mathrm{A}_{2 \mathrm{a}} \mathrm{R}^{-/-}$mice, and there was a significant difference in the release of Cyt $\mathrm{C}$ from the mitochondria to the cytoplasm between the H5HD and HK5HD groups ( $\mathrm{p}<0.05$ ) (Fig. 6f-g); a similarly significant difference between the HDia and HKDia groups was observed ( $<<0.05)$ (Fig. 6h-j). 
331

332

333

Thus, these results indicate that $\mathrm{A}_{2 \mathrm{a}} \mathrm{R}$ activates the mitochondrial-dependent apoptotic pathway partially by blocking the opening of MitoK $\mathrm{ATP}_{\mathrm{A}}$

As shown in Fig. 6k, the expression of Caspase-9 was decreased in the lung tissues of hypoxia-exposed mice $(\mathrm{p}<0.01)$, which was ameliorated by CGS21680 treatment $(\mathrm{p}<0.05)$. Repeated administration of 5HD reversed chronic hypoxia-induced down-regulation of Caspase-9 expression ( $\mathrm{p}<0.01$ ) (Fig. 61), and the expression of Caspase-9 was lower in the HK5HD group than in the H5HD group $(\mathrm{p}<0.05)$, indicating that $\mathrm{A}_{2 \mathrm{a}} \mathrm{R}$ activates the mitochondrial-dependent

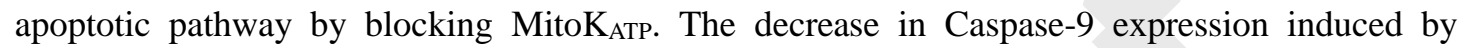
hypoxia was further inhibited by diazoxide treatment $(\mathrm{p}<0.01)($ Fig. 6m).

\section{Discussion}

In this study, we verified that $\mathrm{A}_{2 \mathrm{a}} \mathrm{R}$ and MitoK $_{\mathrm{ATP}}$ both play an important role in the treatment of hypoxic pulmonary arterial hypertension, and that $\mathrm{A} 2 \mathrm{aR}$ can improve $\mathrm{HPH}$ via mitochondrial ATP-sensitive potassium channels.

The vasoconstriction and pulmonary vascular remodeling is the primary pathophysiological features of $\mathrm{PH}[21]$. Humbert et al. found that excessive vasoconstriction is associated with the abnormal expression of potassium channels and dysfunction of endothelial cells [22]. In addition, the primary factor contributing to pulmonary vascular remodeling is the imbalance between proliferation and apoptosis [23]. The purpose of this study was to explore whether MitoK $\mathrm{ATP}_{\text {is }}$ involved in the mechanism underlying improvement of $\mathrm{PH}$ and whether it mediates the function of $\mathrm{A}_{2 \mathrm{a}} \mathrm{R}$ in regulating PASMC apoptosis.

Adenosine is an endogenous purine nucleoside that regulates a series of physiological and 
352

353

pathological processes by binding to adenosine receptors [24]. Recently, the relationship between adenosine and $\mathrm{PH}$ has been a focus of research. In other types of PH models, $\mathrm{A}_{2 \mathrm{a}} \mathrm{R}$ has been confirmed to play an important role in the pathogenesis of PH. Alencar et al. reported that an A2aR agonist can reverse pulmonary vascular remodeling and endothelial dysfunction in rats with monocrotaline-induced $\mathrm{PH}$ [25]. Shang et al. established the $\mathrm{A}_{2 \mathrm{a}} \mathrm{R}$ knockout mice model and found that $\mathrm{A}_{2 \mathrm{a}} \mathrm{R}^{-/-}$mice are more likely to exhibit the pathological features of $\mathrm{PH}[14,26]$. Like previous studies, $\mathrm{A}_{2 \mathrm{a}} \mathrm{R}$ showed the same effects in an HPH animal model. Consistent with the results of this study, these studies all indicate that $\mathrm{A}_{2 \mathrm{a}} \mathrm{R}$ plays an important role in the treatment of $\mathrm{HPH}$.

An imbalance between PASMC proliferation and apoptosis is a primary cause of pulmonary vascular remodeling. It has been found that, in HPH, some drugs can regulate cell apoptosis through $\mathrm{A}_{2 \mathrm{a}} \mathrm{R}$ [27]. Youle et al. reported that members of the Bcl-2 protein family play important roles in regulating apoptosis: Bax promotes the opening of the mitochondrial permeability transition pore to induce apoptosis and Bcl-2 inhibits its opening and prevents apoptosis [28]. In this study, we found that the Bax/Bcl-2 ratio in the lung homogenates with CGS21680 treatment was significantly increased than that of the hypoxia group, objectively proving that the increase in $\mathrm{A}_{2 \mathrm{a}} \mathrm{R}$ expression promotes PASMC apoptosis in the treatment of $\mathrm{HPH}$. Although the Bax/Bcl-2 ratio was significantly decreased in $\mathrm{A}_{2 \mathrm{a}} \mathrm{R}^{-/-}$mice, a certain level was still maintained. These findings indicate that $\mathrm{A}_{2 \mathrm{a}} \mathrm{R}$ partially influences PASMC apoptosis induced by hypoxia.

Dromparis et al. have reported that the mitochondrial-dependent apoptotic pathway plays an important role in the occurrence and development of HPH [29]; our study also supports this view. MitoK $_{\text {ATP }}$ is an important determinant of the mitochondrial membrane potential, which is sensitive to hypoxia. According to a previous study, hypoxia or diazoxide can lead to the depolarization of 
the mitochondrial membrane in PASMCs, thereby ultimately reducing apoptosis in these cells. The results of this study support this conclusion [18]. Moreover, we found that 5HD ameliorates the effects of hypoxia. The RVSP and $\mathrm{RV} /(\mathrm{LV}+\mathrm{S}), \mathrm{RV} / \mathrm{BW}$, WA/TA, and WT/TT ratios in hypoxia-exposed mice were significantly reduced by repeated 5HD treatment, and the ultrastructure of mitochondria in the 5HD group was also relatively intact. Compared with the hypoxia control group, the percentage of PCNA-positive cells in 5HD-treated mice was significantly lower, and the apoptotic index of PASMCs was significantly higher. These findings firmly prove that hypoxia-induced excessive proliferation and apoptosis resistance of PASMCs were inhibited by blocking MitoK $_{\text {АTP }}$ exacerbated by promoting its opening, which contributes to alleviation of $\mathrm{HPH}$.

Our previous study found that A2aR could alleviate $\mathrm{HPH}$ via mitochondrial-dependent apoptotic pathway [27], we further explored whether there is an interaction between $\mathrm{A}_{2 \mathrm{a}} \mathrm{R}$ and $\mathrm{MitoK}$ ATP. In our study, the ability of 5HD to improve pathological changes of HPH was significantly inhibited in $\mathrm{A}_{2 \mathrm{a}} \mathrm{R}^{-/-}$mice than that in WT mice. The RVSP, RV/(LV+S), RV/BW, WA/TA, and WT/TT values in the $\mathrm{A}_{2 \mathrm{a}} \mathrm{R}^{-/}$group treated with 5HD were significantly higher than those in the WT group. Coincidentally, the initial components of the mitochondrial-dependent apoptotic pathway are apoptosis-regulating proteins of the $\mathrm{Bcl}-2$ protein family. Within this family, Bax is a pro-apoptotic protein and $\mathrm{Bcl}-2$ is an anti-apoptotic protein, and down-regulation of $\mathrm{Bax} / \mathrm{Bcl}-2$ in the mitochondrial apoptotic pathway inhibits the release of Cyt $\mathrm{C}$ and Caspase-9. Bax promotes the release of mitochondrial Cyt $\mathrm{C}$ into the cytoplasm and then activates Caspase- 9 to produce a cascade reaction [28]. To explore whether $\mathrm{A}_{2 \mathrm{a}} \mathrm{R}$-induced blocking of MitoK $\mathrm{K}_{\mathrm{AT}}$ could activate the mitochondrial-dependent apoptotic pathway, we detected the expression of Bax, Bcl-2, Cyt C, and 
396

397

398

399

400

401

402

403

Caspase 9. We found that deletion of $\mathrm{A}_{2 \mathrm{a}} \mathrm{R}$ diminished the positive effect of the MitoK $\mathrm{ATP}_{\text {blocker }}$ on the mitochondrial apoptotic pathway. This indicates that $\mathrm{A}_{2 \mathrm{a}} \mathrm{R}$ up-regulates the expression of Bax partially by blocking MitoK $\mathrm{K}_{\mathrm{ATP}}$ and that $\mathrm{A}_{2 \mathrm{a}} \mathrm{R}$ thus prevents $\mathrm{HPH}$ via blocking MitoK $\mathrm{K}_{\mathrm{ATP}}$.

Endogenous nitric oxide (NO) has been reported to promote mitokATP channel opening [30], and its inhibitor can block the cardioprotective effect induced by mitokATP channel inhibitor diazoxide [31]. A recent study found that A2a receptor agonist could suppress the expression of NO synthase protein, thus inhibited the release of NO [32]. In conclusion, A2aR may block the MitoKATP channels by decreasing the expression of NO. But the certain mechanisms between the A2aR and MitoKATP channel remains to be further verified.

In this study, we established a hypoxic animal model and verified that $\mathrm{A}_{2 \mathrm{a}} \mathrm{R}$ and MitoK $\mathrm{KTP}_{\mathrm{b}}$ both play an important role in the treatment of $\mathrm{HPH}$, and we demonstrated an interaction between the two. $\mathrm{A}_{2 \mathrm{a}} \mathrm{R}$ can activate the mitochondrial-dependent apoptotic pathway and inhibit PASMC proliferation partially by blocking the opening of MitoK $\mathrm{ATP}_{\mathrm{A}}$, thereby alleviating pulmonary vascular structural remodeling and attenuating $\mathrm{HPH}$. The specific mechanism between $\mathrm{A}_{2 \mathrm{a}} \mathrm{R}$ and

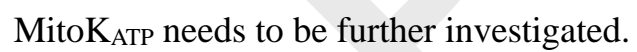

\section{Conclusions}

This study showed that an increase in $\mathrm{A}_{2 \mathrm{a}} \mathrm{R}$ and blocking of MitoK $\mathrm{KTP}_{\mathrm{A}}$ alleviate HPH. Furthermore, $\mathrm{A}_{2 \mathrm{a}} \mathrm{R}$ induced the mitochondrial-dependent apoptosis pathway and inhibited PASMC proliferation by blocking MitoK $_{\mathrm{ATP}}$, thereby alleviating pulmonary vascular structural remodeling and reducing HPH. This study further elucidated the pathogenesis of HPH and explored the mechanism of action of $\mathrm{A}_{2 \mathrm{a}} \mathrm{R}$. 


\section{Acknowledgments}

418

This research was supported by Chinese National Natural Science Foundation Grants [grant number 81473406]; Zhejiang Provincial Natural Science Foundation of China [grant number LQ19H010003]; and the Project of Health Commission of Zhejiang Province [grant number 2019RC047].

\section{Abbreviations}

PH: pulmonary hypertension; HPH: hypoxia-induced pulmonary hypertension; $\mathrm{A}_{2 \mathrm{a}} \mathrm{R}$ : $\mathrm{A}_{2 \mathrm{a}}$ receptors; MitoK $_{\mathrm{ATP}}$ : mitochondrial ATPsensitive potassium channels; WT: wild-type; $\mathrm{A}_{2 \mathrm{a}} \mathrm{R}^{-/-}: \mathrm{A}_{2 \mathrm{a}} \mathrm{R}-$ deficient; Dia: diazoxide; 5HD: 5-hydroxydecanoic acid sodium salt; PASMCs: pulmonary artery smooth muscle cells; PCNA: proliferating cell nuclear antigen; $\Delta \psi \mathrm{m}$ : mitochondrial membrane potential; HE: hematoxylineosin; RVSP: right ventricular systolic pressure; mCAP: mean carotid arterial pressure; RV: right ventricle; LV: left ventricle; S, septum; BW: body weight; WA: wall area; TA: total area; WT: wall thickness; TT: total thickness; NO, nitric oxide.

\section{Compliance with ethics guidelines}

All institutional and national guidelines for the care and use of laboratory animals were followed.

All experimental protocols conformed to the Guide for the Care and Use of Laboratory Animals, which was published by the US National Institutes of Health, and were approved by the Animal

Ethics Committee of Wenzhou Medical University.

\section{Competing interests}

The authors have declared that no competing interest exists.

\section{Availability of data and material}

All relevant data and materials are stored in the Key Laboratory of Heart and Lung of Wenzhou 


\section{References}

1. Nathan SD, Hassoun PM. Pulmonary hypertension due to lung disease and/or hypoxia. Clin Chest Med 2013;34(4):695-705.

2. Tang H, Desai AA, Yuan JX. Genetic Insights into Pulmonary Arterial Hypertension. Application of Whole-Exome Sequencing to the Study of Pathogenic Mechanisms. Am J Respir Crit Care Med 2016;194(4):393-7.

3. Galiè N, Channick RN, Frantz RP, Grünig E, Jing ZC, Moiseeva O, Preston IR, Pulido T, Safdar Z, Tamura Y, McLaughlin VV. Risk stratification and medical therapy of pulmonary arterial hypertension. Eur Respir J 2019;53(1).

4. Coons JC, Pogue K, Kolodziej AR, Hirsch GA, George MP. Pulmonary Arterial Hypertension: a Pharmacotherapeutic Update. Curr Cardiol Rep 2019;21(11):141.

5. Ma L, Chung WK. The role of genetics in pulmonary arterial hypertension. J Pathol 2017;241(2):273-80.

6. Young A, Ngiow SF, Gao Y, Patch AM, Barkauskas DS, Messaoudene M, Lin G, Coudert JD, Stannard KA, Zitvogel L, Degli-Esposti MA, Vivier E, Waddell N, Linden J, Huntington ND, Souza-Fonseca-Guimaraes F, Smyth MJ. A2AR Adenosine Signaling Suppresses Natural Killer Cell Maturation in the Tumor Microenvironment. Cancer Res 2018;78(4):1003-16.

7. TK Jeffery, JC Wanstall. Pulmonary vascular remodeling: a target for therapeutic intervention in pulmonary hypertension. Pharmacol Therapeut 2001;92(1):1-20.

8. AAR Thompson, A Lawrie. Targeting Vascular Remodeling to Treat Pulmonary Arterial Hypertension. Trends Mol Med 2017;23(1):31-45.

9. A Bourgeois, J Omura, K Habbout, S Bonnet, O Boucherat. Pulmonary arterial hypertension: New pathophysiological insights and emerging therapeutic targets. Int J Biochem Cell B 2018;104:9-13.

10. S Bonnet, D Gomez. RNA Methylation: A New Regulator of Vascular Remodeling in Pulmonary Hypertension. Am J Resp Crit Care 2021

11. Gazoni LM, Walters DM, Unger EB, Linden J, Kron IL, Laubach VE. Activation of A1, A2A, or A3 adenosine receptors attenuates lung ischemia-reperfusion injury. J Thorac Cardiovasc Surg 2010;140(2):440-6.

12. Fredholm BB, Chen JF, Cunha RA, Svenningsson P, Vaugeois JM. Adenosine and brain function. Int Rev Neurobiol 2005;63:191-270.

13. Schindler CW, Karcz-Kubicha M, Thorndike EB, Müller CE, Tella SR, Ferré S, Goldberg SR. Role of central and peripheral adenosine receptors in the cardiovascular responses to intraperitoneal injections of adenosine A1 and A2A subtype receptor agonists. Br J Pharmacol 2005;144(5):642-50.

14. Xu MH, Gong YS, Su MS, Dai ZY, Dai SS, Bao SZ, Li N, Zheng RY, He JC, Chen JF, Wang XT. Absence of the adenosine A2A receptor confers pulmonary arterial hypertension and increased pulmonary vascular remodeling in mice. J Vasc Res 2011;48(2):171-83.

15. Huang X, Wu P, Huang F, Xu M, Chen M, Huang K, Li GP, Xu M, Yao D, Wang L. Baicalin attenuates chronic hypoxia-induced pulmonary hypertension via adenosine A receptor-induced SDF-1/CXCR4/PI3K/AKT signaling. J Biomed Sci 2017;24(1):52.

16. Olschewski A, Papp R, Nagaraj C, Olschewski H. Ion channels and transporters as therapeutic targets in the pulmonary circulation. Pharmacol Ther 2014;144(3):349-68.

17. Ward JP, McMurtry IF. Mechanisms of hypoxic pulmonary vasoconstriction and their roles in pulmonary hypertension: new findings for an old problem. Curr Opin Pharmacol 2009;9(3):287-96. 
18. Hu HL, Zhang ZX, Chen CS, Cai C, Zhao JP, Wang X. Effects of mitochondrial potassium channel and membrane potential on hypoxic human pulmonary artery smooth muscle cells. Am $\mathbf{J}$ Respir Cell Mol Biol 2010;42(6):661-6.

19. Hu H, Ding Y, Wang Y, Geng S, Liu J, He J, Lu Y, Li X, Yuan M, Zhu S, Zhao S. MitoK channels promote the proliferation of hypoxic human pulmonary artery smooth muscle cells via the ROS/HIF/miR-210/ISCU signaling pathway. Exp Ther Med 2017;14(6):6105-12.

20. Berwick ZC, Payne GA, Lynch B, Dick GM, Sturek M, Tune JD. Contribution of adenosine A(2A) and $\mathrm{A}(2 \mathrm{~B})$ receptors to ischemic coronary dilation: role of $\mathrm{K}(\mathrm{V})$ and $\mathrm{K}(\mathrm{ATP})$ channels. Microcirculation 2010;17(8):600-7.

21. Cogolludo A, Moreno L, Villamor E. Mechanisms controlling vascular tone in pulmonary arterial hypertension: implications for vasodilator therapy. Pharmacology 2007;79(2):65-75.

22. Humbert M, Morrell NW, Archer SL, Stenmark KR, MacLean MR, Lang IM, Christman BW, Weir EK, Eickelberg O, Voelkel NF, Rabinovitch M. Cellular and molecular pathobiology of pulmonary arterial hypertension. J Am Coll Cardiol 2004;43:13S-24S.

23. Ball MK, Waypa GB, Mungai PT, Nielsen JM, Czech L, Dudley VJ, Beussink L, Dettman RW, Berkelhamer SK, Steinhorn RH, Shah SJ, Schumacker PT. Regulation of hypoxia-induced pulmonary hypertension by vascular smooth muscle hypoxia-inducible factor-1 $\alpha$. Am J Respir Crit Care Med 2014;189(3):314-24.

24. Manjunath S, Sakhare PM. Adenosine and adenosine receptors: Newer therapeutic perspective. Indian J Pharmacol 2009;41(3):97-105.

25. Alencar AK, Pereira SL, Montagnoli TL, Maia RC, Kümmerle AE, Landgraf SS, Caruso-Neves C, Ferraz EB, Tesch R, Nascimento JH, de Sant'Anna CM, Fraga CA, Barreiro EJ, Sudo RT, Zapata-Sudo G. Beneficial effects of a novel agonist of the adenosine A2A receptor on monocrotaline-induced pulmonary hypertension in rats. Br J Pharmacol 2013;169(5):953-62.

26. Shang P, He ZY, Chen JF, Huang SY, Liu BH, Liu HX, Wang XT. Absence of the Adenosine A2A Receptor Confers Pulmonary Arterial Hypertension Through RhoA/ROCK Signaling Pathway in Mice. J Cardiovasc Pharmacol 2015;66(6):569-75.

27. Huang X, Zou L, Yu X, Chen M, Guo R, Cai H, Yao D, Xu X, Chen Y, Ding C, Cai X, Wang L. Salidroside attenuates chronic hypoxia-induced pulmonary hypertension via adenosine A2a receptor related mitochondria-dependent apoptosis pathway. J Mol Cell Cardiol 2015;82:153-66.

28. Youle RJ, Strasser A. The BCL-2 protein family: opposing activities that mediate cell death. Nat Rev Mol Cell Biol 2008;9(1):47-59.

29. Dromparis P, Sutendra G, Michelakis ED. The role of mitochondria in pulmonary vascular remodeling. J Mol Med (Berl) 2010;88(10):1003-10.

30. Sasaki N, Sato T, Ohler A, O'Rourke B, and Marban E. Activation of mitochondrial ATP-dependent potassium channels by nitric oxide. Circulation 2000;101(4):439-45.

31. Ockaili R, Emani VR, Okubo S, Brown M, Krottapalli K, and Kukreja RC. Opening of mitochondrial KATP channel induces early and delayed cardioprotective effect: role of nitric oxide. Am J Physiol 1999;277(6):H2425-H34.

32. Kwilasz AJ, Green Fulgham SM, Ellis A, Patel HP, Duran-Malle JC, Favret J, Harvey LO, Rieger J, Maier SF, Watkins LR. A single peri-sciatic nerve administration of the adenosine 2A receptor agonist ATL313 produces long-lasting anti-allodynia and anti-inflammatory effects in male rats. Brain Behav Immun 2019;76:116-25. 


\section{Figure Legends}

Fig. $1 \mathrm{~A}_{2 \mathrm{a}} \mathrm{R}$ reversed hypoxia-induced opening of MitoK $\mathrm{ATP}_{\mathrm{in}}$ PASMCs

$\mathrm{A}_{2 \mathrm{a}} \mathrm{R}$ protein expression levels in PASMCs transfected with siCTRL and $\mathrm{si}_{2 \mathrm{a}} \mathrm{R}$ under normoxic

(Nor) and hypoxic $\left(5 \% \mathrm{O}_{2}\right)$ conditions for $48 \mathrm{~h}$ (a). Using the fluorescence intensity of Rhodamine 123 to indicate the opening level of MitoK $_{\text {ATP }}$ in PASMCs of different groups (b). Representative micrographs of rhodamine-123 fluorescence intensity in PASMCs (c). Data are presented as the mean \pm standard deviation $(\mathrm{SD})$. \# $p<0.05$, \#\# $p<0.01$ vs normoxic group; $* p<0.05$, ** $p<$ 0.01 vs hypoxic group; $+p<0.05,++p<0.01$ between $\mathrm{A}_{2 \mathrm{a}} \mathrm{R}^{-/-}$and WT mice groups. $\mathrm{A}_{2 \mathrm{a}} \mathrm{R}$ : $\mathrm{A}_{2 \mathrm{a}}$ receptors; MitoK $\mathrm{ATP}$ : mitochondrial ATPsensitive potassium channels; PASMCs, pulmonary artery smooth muscle cells.

Fig. 2 A 2 R alleviated hypoxia-induced hemodynamic changes via MitoK ATP

Effects of CGS21680 (+CGS, $0.2 \mathrm{mg} / \mathrm{kg} /$ day), 5HD (+5HD, $10 \mathrm{mg} / \mathrm{kg} / \mathrm{day})$, and Dia (+Dia, $7 \mathrm{mg}$ $/ \mathrm{kg} /$ day) on $\mathrm{A}_{2 \mathrm{a}} \mathrm{R}$ protein expression levels in lung homogenates of mice exposed to hypoxic conditions $\left(10 \% \mathrm{O}_{2}\right)$ or ambient oxygen levels $\left(21 \% \mathrm{O}_{2}\right)$ for 4 weeks were examined by western blotting (a; $n=3)$. Effects of CGS21680 (+CGS, $0.2 \mathrm{mg} / \mathrm{kg} / \mathrm{day}), 5 \mathrm{HD}(+5 \mathrm{HD}, 10 \mathrm{mg} / \mathrm{kg} / \mathrm{day})$, and Dia (+Dia, $7 \mathrm{mg} / \mathrm{kg} /$ day) on $\operatorname{RVSP}(\mathrm{b} ; n=6)$ and $\operatorname{mCAP}(\mathrm{c} ; n=6)$ in WT and $\mathrm{A}_{2 \mathrm{a}} \mathrm{R}^{-/-}$mice. Representative pictures of RVSP waves (red) in the WT and $\mathrm{A}_{2 \mathrm{a}} \mathrm{R}^{-/-}$groups (d). Representative pictures of mCAP waves (blue) in the $\mathrm{WT}$ and $\mathrm{A}_{2 \mathrm{a}} \mathrm{R}^{-/-}$groups (e). Data are presented as the mean \pm standard deviation (SD). \# $p<0.05$, \#\# $p<0.01$ vs normoxic group; * $p<0.05, * * p<0.01$ vs hypoxic group; $+p<0.05,++p<0.01$ between $\mathrm{A}_{2 \mathrm{a}} \mathrm{R}^{-/-}$and WT mice groups. $\mathrm{A}_{2 \mathrm{a}} \mathrm{R}$ : $\mathrm{A}_{2 \mathrm{a}}$ receptors;

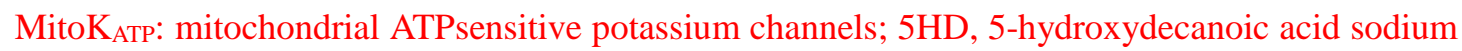


salt; Dia, diazoxide; RVSP, right ventricular systolic pressure; mCAP, mCAP; WT, wild-type.

Fig. $3 A_{2 a} R$ alleviated hypoxia-induced RV hypertrophy and pulmonary arterial remodeling via MitoK $_{\mathrm{ATP}}$

Effects of CGS21680 (+CGS, $0.2 \mathrm{mg} / \mathrm{kg} / \mathrm{day}), 5 \mathrm{HD}$ (+5HD, $10 \mathrm{mg} / \mathrm{kg} / \mathrm{day})$, and Dia (+Dia, $7 \mathrm{mg}$ $/ \mathrm{kg} / \mathrm{day})$ on the $\mathrm{RV} /(\mathrm{LV}+\mathrm{S})(\mathrm{a} ; n=10), \mathrm{RV} / \mathrm{BW}(\mathrm{b} ; n=10), \mathrm{WT} / \mathrm{TT}(\%)(\mathrm{d} ; n=10)$, and $\mathrm{WA} / \mathrm{TA}(\%)(\mathrm{e} ; n=10)$ ratios in $\mathrm{WT}$ and $\mathrm{A}_{2 \mathrm{a}} \mathrm{R}^{-/-}$mice. Representative photomicrographs showing hypoxia-induced remodeling in the pulmonary arteries of the WT and $\mathrm{A}_{2 \mathrm{a}} \mathrm{R}^{-/-}$groups exposed to hypoxia $\left(10 \% \mathrm{O}_{2}\right)$ or ambient oxygen levels $\left(21 \% \mathrm{O}_{2}\right)$ for 4 weeks $(\mathrm{c}, \times 400)$, the white arrow indicates the pulmonary artery. Data are presented as the mean \pm standard deviation (SD). \# $p<$ 0.05 , \# $p<0.01$ vs normoxic group; * $p<0.05, * * p<0.01$ vs hypoxic group $+p<0.05,++p<$ 0.01 between $\mathrm{A}_{2 \mathrm{a}} \mathrm{R}^{-/-}$and WT mice groups. $\mathrm{A}_{2 \mathrm{a}} \mathrm{R}$ : $\mathrm{A}_{2 \mathrm{a}}$ receptors; MitoK $\mathrm{K}_{\mathrm{ATP}}$ : mitochondrial ATPsensitive potassium channels; 5HD, 5-hydroxydecanoic acid sodium salt; Dia, diazoxide; RV, right ventricle; LV, left ventricle; S, septum; BW, body weight; WT, wall thickness; TT, total thickness; WA, wall area; TA, total area; WT, wild-type.

Fig. $4 A_{2 a} R$ alleviated hypoxia-induced excessive proliferation and apoptosis resistance in PASMCs via MitoK ATP

Representative photomicrographs of PCNA (brown) expression in the pulmonary arteries of WT and $\mathrm{A}_{2 \mathrm{a}} \mathrm{R}^{-/}$groups $(\mathrm{a}, \times 400)$, the black arrow indicates the PCNA in the pulmonary arteries. Representative photomicrographs of apoptotic cells (brown) in the pulmonary arteries of WT and $\mathrm{A}_{2 \mathrm{a}} \mathrm{R}^{-/-}$groups $(\mathrm{b}, \times 400)$, the black arrow indicates the apoptotic cells in the pulmonary arteries. PCNA expression levels in PASMCs were examined by immunohistochemistry, and apoptosis 
levels of PASMCs were examined by TUNEL assay. Effects of CGS21680 (+CGS, 0.2 $\mathrm{mg} / \mathrm{kg} /$ day), 5HD (+5HD, $10 \mathrm{mg} / \mathrm{kg} /$ day), and Dia (+Dia, $7 \mathrm{mg} / \mathrm{kg} /$ day) on PCNA expression in PASMCs (c; $n=5)$, and the apoptosis of PASMCs $(\mathrm{d} ; n=5)$ in $\mathrm{WT}$ and $\mathrm{A}_{2 \mathrm{a}} \mathrm{R}^{-/-}$mice. Data are presented as the mean \pm standard deviation (SD). \# $p<0.05$, \#\# $p<0.01$ vs normoxic group; $* p<$ $0.05, * * p<0.01$ vs hypoxic group $+p<0.05,++p<0.01$ between $\mathrm{A}_{2 \mathrm{a}} \mathrm{R}^{-/-}$and WT mice groups. $\mathrm{A}_{2 \mathrm{a}} \mathrm{R}: \mathrm{A}_{2 \mathrm{a}}$ receptors; MitoK $\mathrm{ATP}_{\mathrm{ATP}}$ mitochondrial ATPsensitive potassium channels; PCNA, proliferating cell nuclear antigen; WT, wild-type; PASMCs, pulmonary artery smooth muscle cells; 5HD, 5-hydroxydecanoic acid sodium salt; Dia, diazoxide.

Fig. $5 A_{2 a} R$ alleviated hypoxia-induced apoptosis resistance in PASMCs via MitoK $_{A T P}$

Bax and Bcl-2 expression levels in lung homogenates were examined by western blotting. Effects of CGS21680 (+CGS, $0.2 \mathrm{mg} / \mathrm{kg} / \mathrm{day}$ ) on Bax and Bcl-2 expression in lung homogenates of WT mice (a, d; $n=3)$. Effects of 5HD (+5HD, $10 \mathrm{mg} / \mathrm{kg} /$ day) on Bax and Bcl-2 expression in lung homogenates of WT and $\mathrm{A}_{2 \mathrm{a}} \mathrm{R}^{-/}$mice (b, e; $n=3$ ). Effects of Dia (+Dia, $7 \mathrm{mg} / \mathrm{kg} / \mathrm{day}$ ) on Bax and Bcl-2 expression in lung homogenates of $\mathrm{WT}$ and $\mathrm{A}_{2 \mathrm{a}} \mathrm{R}^{-/-}$mice (c, f; $n=3$ ). Protein expression ratios of $\mathrm{Bax}$ to $\mathrm{Bcl}-2$ were also calculated (g, h, and $\mathrm{i} ; n=3$ ). Data are presented as the mean \pm standard deviation (SD). \# $p<0.05$, \# $p<0.01$ vs normoxic group; ${ }^{*} p<0.05$, ** $p<0.01$ vs hypoxic group; $+p<0.05,++p<0.01$ between $\mathrm{A}_{2 \mathrm{a}} \mathrm{R}^{-/-}$and WT mice groups. $\mathrm{A}_{2 \mathrm{a}} \mathrm{R}$ : $\mathrm{A}_{2 \mathrm{a}}$ receptors; MitoK $_{\text {ATP: }}$ mitochondrial ATPsensitive potassium channels; WT, wild-type; 5HD, 5-hydroxydecanoic acid sodium salt; Dia, diazoxide.

Fig. $6 A_{2 a} R$ modulated cell apoptosis via the mitochondrial-dependent apoptosis pathway 
Effects of CGS21680 (+CGS, $0.2 \mathrm{mg} / \mathrm{kg} / \mathrm{day}), 5 \mathrm{HD}$ (+5HD, $10 \mathrm{mg} / \mathrm{kg} / \mathrm{day})$, and Dia (+Dia, 7 $\mathrm{mg} / \mathrm{kg} / \mathrm{day}$ ) on $\mathrm{PH}$ at the ultrastructure level. Ultrathin sections of lung tissues from WT and $\mathrm{A}_{2 \mathrm{a}} \mathrm{R}^{-/-}$mice were observed by a Hitachi H-7500 transmission electron microscopy $(\mathrm{a}, \times 20000)$, the white arrow indicates the mitochondria. The expression levels of cytochrome $\mathrm{C}$ in mitochondrial and cytosol pellets and Caspase-9 in lung tissue were examined by western blotting with antibodies against cytochrome $\mathrm{C}$ with COX IV as a mitochondria marker and GAPDH as the internal control. Effects of CGS21680 (+CGS, $0.2 \mathrm{mg} / \mathrm{kg} /$ day) on cytochrome C in mitochondrial and cytosol pellets and Caspase-9 expression in lung homogenate of WT mice (b, c, k; $n=3)$.

Effects of $5 \mathrm{HD}(+5 \mathrm{HD}, 10 \mathrm{mg} / \mathrm{kg} /$ day) on cytochrome $\mathrm{C}$ in mitochondrial and cytosol pellets and Caspase-9 expression in lung homogenate of WT mice (e, f, $1 ; n=3$ ). Effects of Dia (+Dia, 7 $\mathrm{mg} / \mathrm{kg} / \mathrm{day}$ ) on cytochrome $\mathrm{C}$ in mitochondrial and cytosol pellets and Caspase-9 expression in lung homogenate of WT mice ( $h, \mathrm{i}, \mathrm{m} ; n=3)$. Protein expression ratios of cytochrome $\mathrm{C}$ in mitochondrial and cytosol pellets were also calculated $(\mathrm{d}, \mathrm{g}, \mathrm{j} ; n=3)$. Data are presented as the mean \pm standard deviation (SD). \# $p<0.05$, \# $p<0.01$ vs normoxic group; $* p<0.05, * * p<$ 0.01 vs hypoxic group; $+p<0.05,++p<0.01$ between $\mathrm{A}_{2 \mathrm{a}} \mathrm{R}^{-/}$and WT mice groups. $\mathrm{A}_{2 \mathrm{a}} \mathrm{R}: \mathrm{A}_{2 \mathrm{a}}$ receptors; 5HD, 5-hydroxydecanoic acid sodium salt; Dia, diazoxide; PH, pulmonary hypertension; WT, wild-type.

Fig. $7 \mathrm{~A}_{2 \mathrm{a}} \mathrm{R}$ attenuated HPH via MitoK $_{\mathrm{ATP}}$

$\mathrm{A}_{2 \mathrm{a}} \mathrm{R}$ attenuated $\mathrm{HPH}$ by modulating the mitochondrial-dependent apoptosis pathway via MitoK $_{\text {ATP. }}$ HPH, hypoxia-induced pulmonary hypertension. 
a

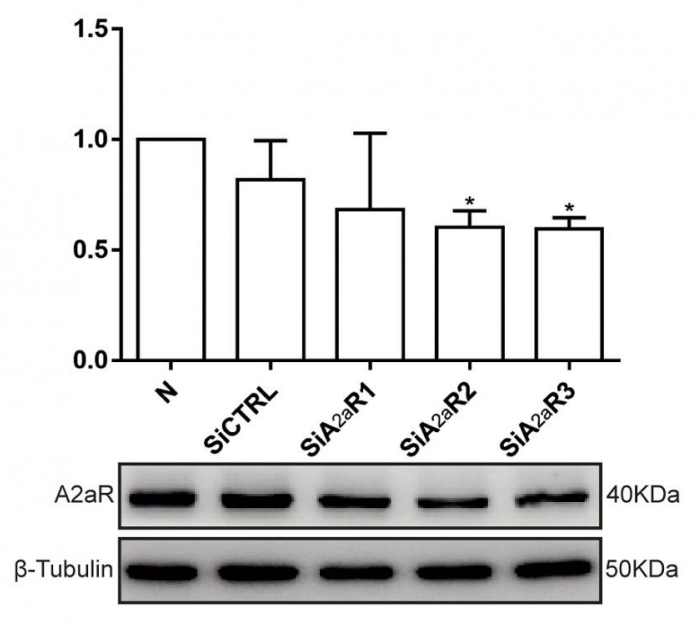

C
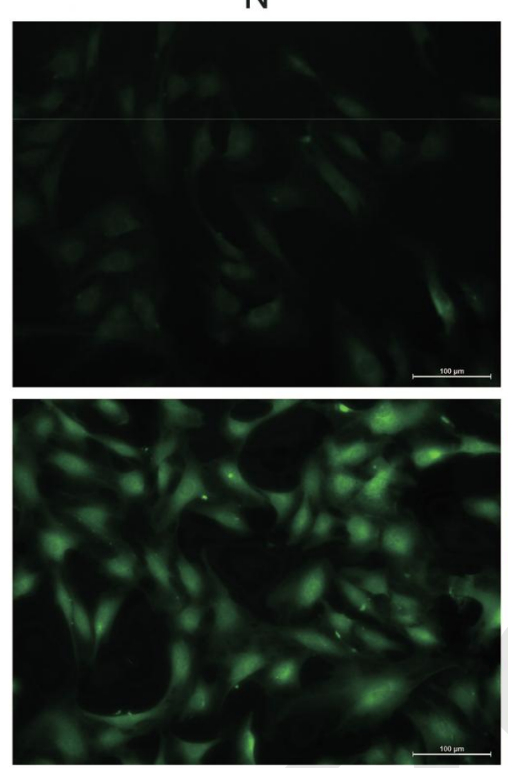

$\mathrm{H}$ b

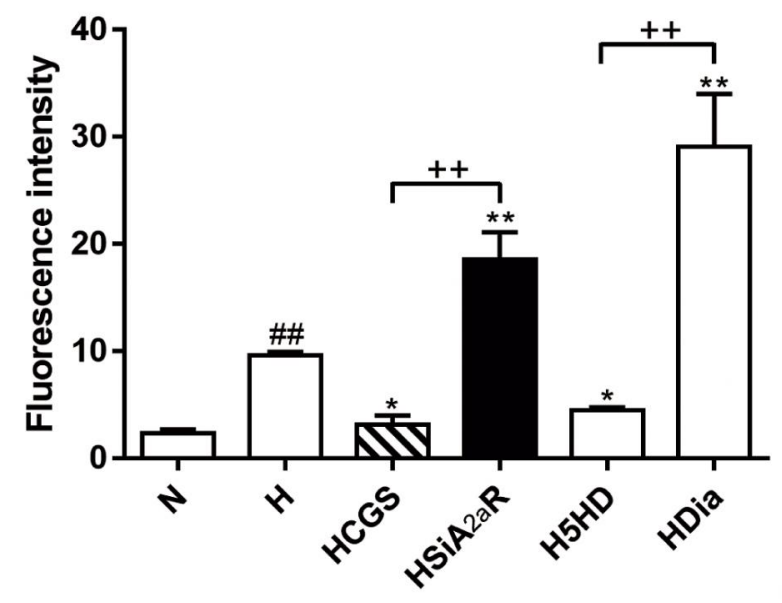

$\mathrm{H} 5 \mathrm{HD}$
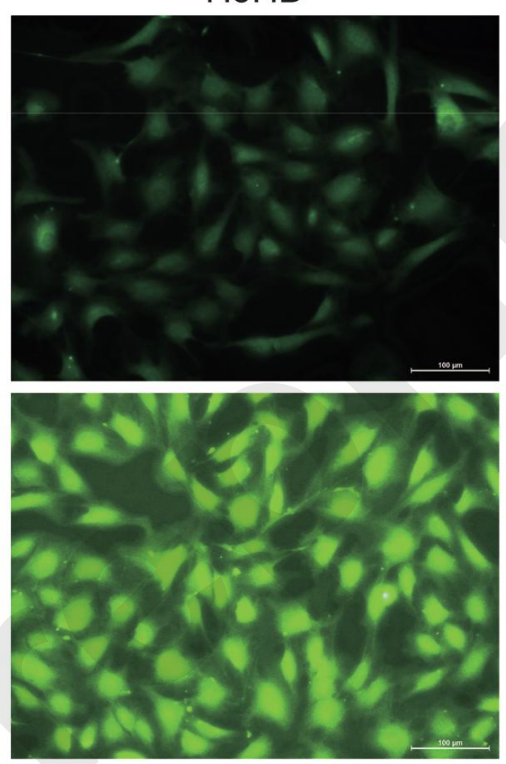

HDia
HCGS
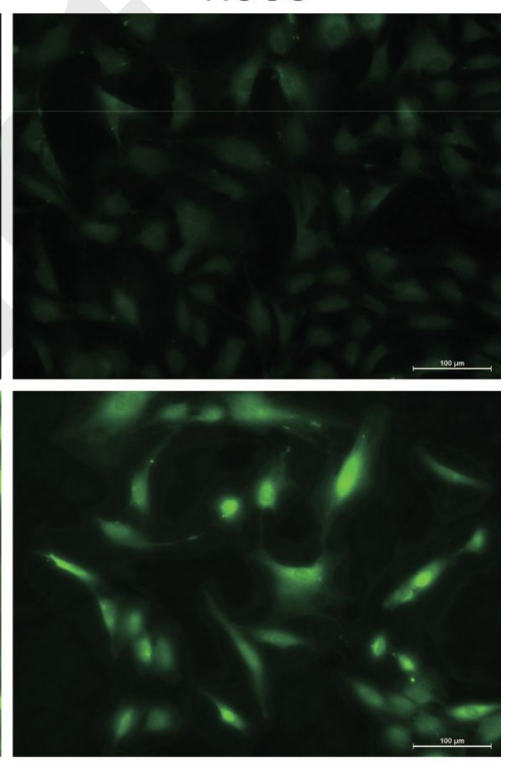

HSiA2aR

Fig. 1 A2aR reversed hypoxia-induced opening of MitoKATP in PASMCs

A2aR protein expression levels in PASMCs transfected with siCTRL and siA2aR under normoxic (Nor) and hypoxic ( $5 \% \mathrm{O} 2)$ conditions for $48 \mathrm{~h}(\mathrm{a})$. Using the fluorescence intensity of Rhodamine 123 to indicate the opening level of MitoKATP in PASMCs of different groups (b). Representative micrographs of rhodamine-123 fluorescence intensity in PASMCs (c). Data are presented as the mean \pm standard deviation (SD). \#p<0.05, \#\#p< 0.01 vs normoxic group; ${ }^{*} p<0.05,{ }^{* *} p<0.01$ vs hypoxic group; $+p<0.05,++p<0.01$ between A2aR-/- and WT mice groups. A2aR: A2a receptors; MitoKATP: mitochondrial ATPsensitive potassium channels; PASMCs, pulmonary artery smooth muscle cells. 


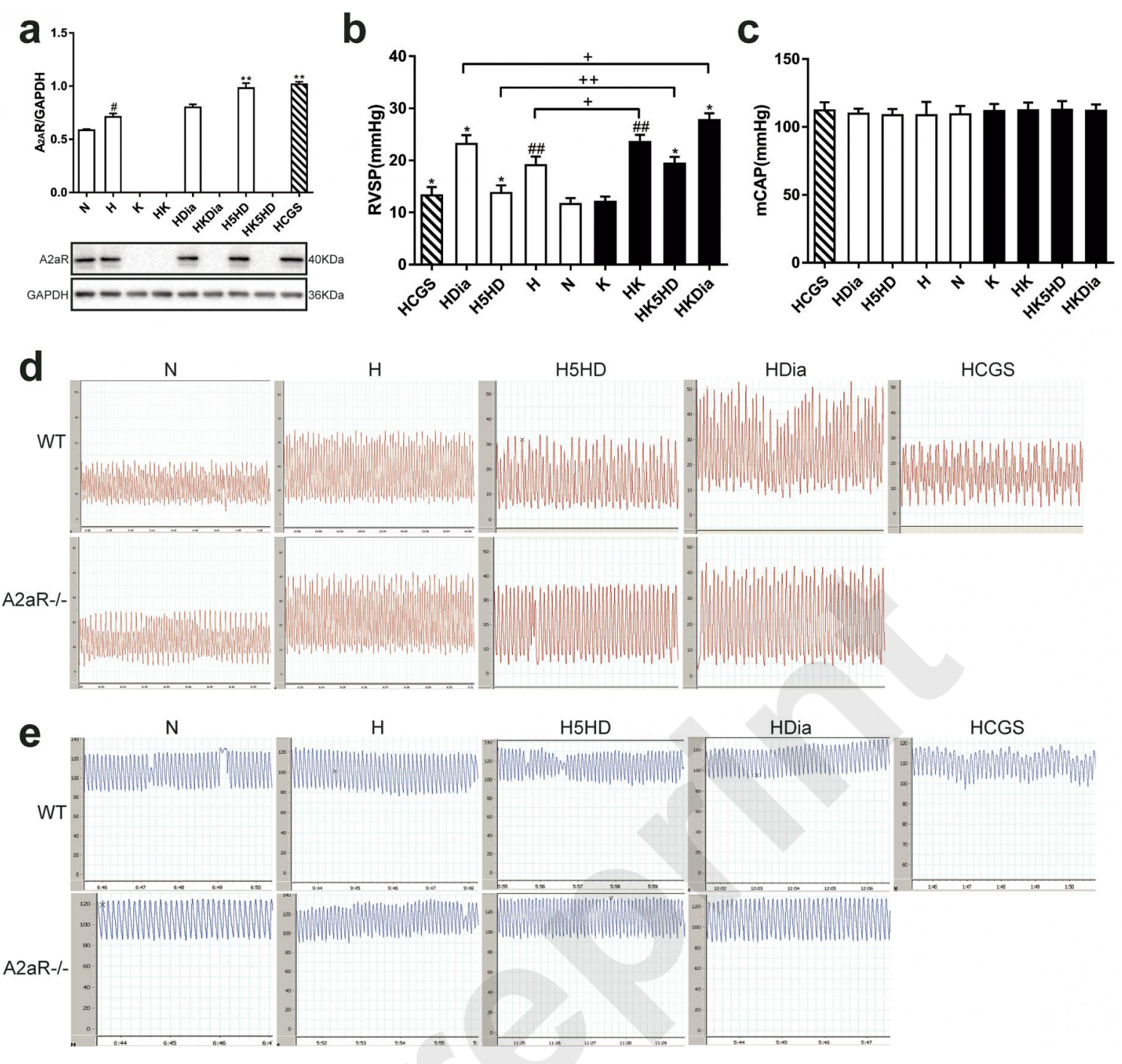

Fig. 2 A2aR alleviated hypoxia-induced hemodynamic changes via MitoKATP Effects of CGS21680 (+CGS, $0.2 \mathrm{mg} / \mathrm{kg} / \mathrm{day}$ ), 5HD (+5HD, $10 \mathrm{mg} / \mathrm{kg} / \mathrm{day}$ ), and Dia (+Dia, 7 $\mathrm{mg} / \mathrm{kg} /$ day) on A2aR protein expression levels in lung homogenates of mice exposed to hypoxic conditions $(10 \% \mathrm{O} 2)$ or ambient oxygen levels $(21 \% \mathrm{O} 2)$ for 4 weeks were examined by western blotting ( $\mathrm{a} ; \mathrm{n}=3$ ). Effects of CGS21680 (+CGS, $0.2 \mathrm{mg} / \mathrm{kg} / \mathrm{day}), 5 \mathrm{HD}$ (+5HD, $10 \mathrm{mg} / \mathrm{kg} / \mathrm{day}$ ), and Dia (+Dia, $7 \mathrm{mg} / \mathrm{kg} /$ day) on RVSP (b; $\mathrm{n}=6)$ and mCAP (c; $\mathrm{n}=$ 6 ) in WT and A2aR-/- mice. Representative pictures of RVSP waves (red) in the WT and A2aR-/- groups (d). Representative pictures of mCAP waves (blue) in the WT and A2aR-/groups (e). Data are presented as the mean \pm standard deviation (SD). \# $p<0.05$, \#\# $p<$ 0.01 vs normoxic group; ${ }^{*} p<0.05,{ }^{* *} p<0.01$ vs hypoxic group; $+p<0.05,++p<0.01$ between A2aR-/- and WT mice groups. A2aR: A2a receptors; MitoKATP: mitochondrial ATPsensitive potassium channels; 5HD, 5-hydroxydecanoic acid sodium salt; Dia, diazoxide; RVSP, right ventricular systolic pressure; mCAP, mCAP; WT, wild-type. 
a

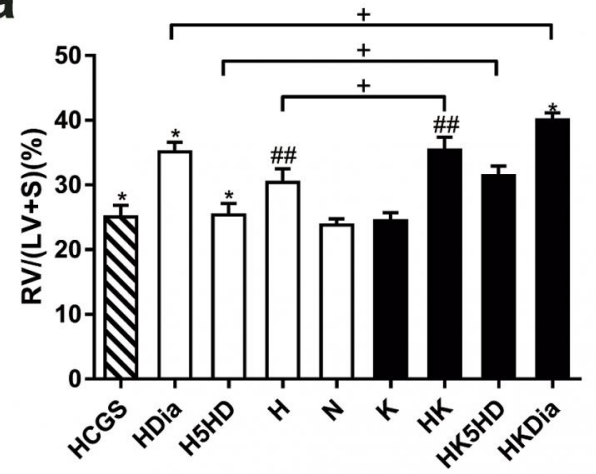

b

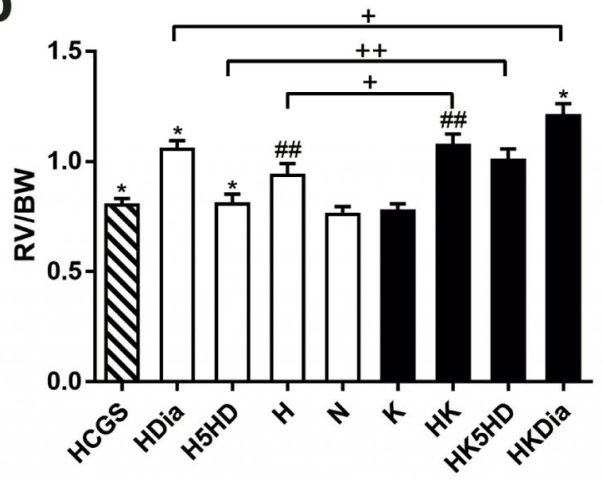

C $\mathrm{N}$ $\mathrm{H}$ $\mathrm{H} 5 \mathrm{HD}$ HDia HCGS
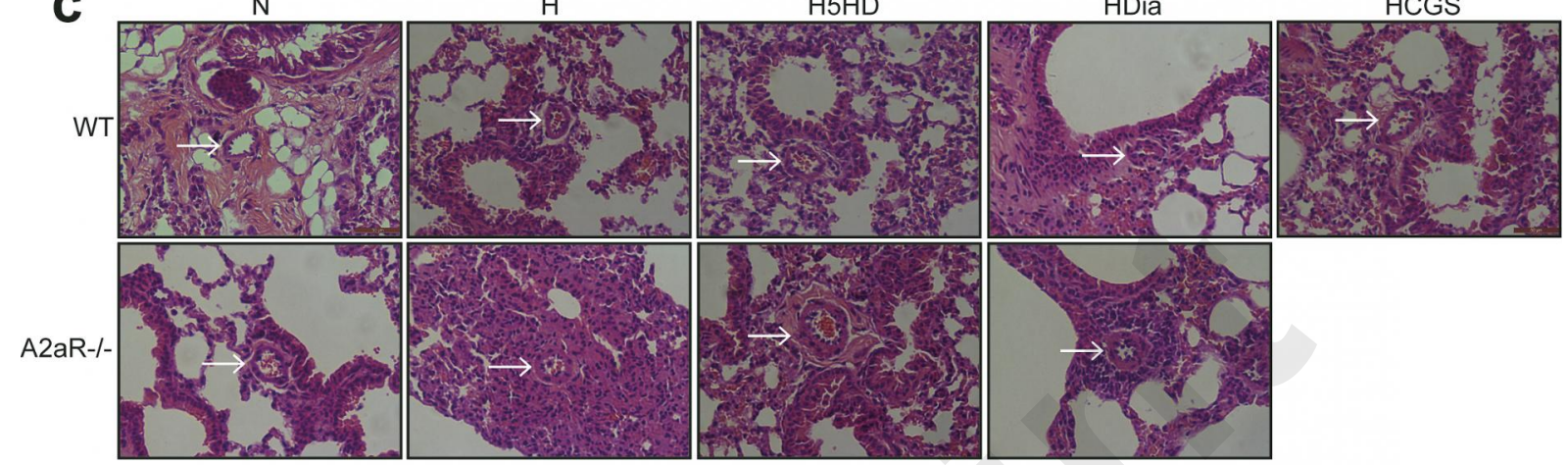

d

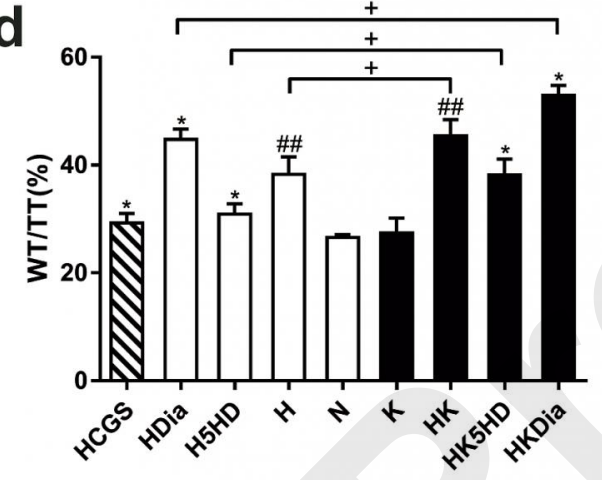

e

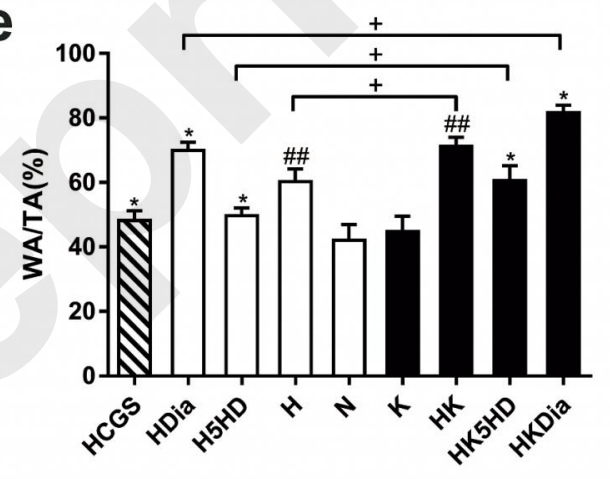

Fig. 3 A2aR alleviated hypoxia-induced RV hypertrophy and pulmonary arterial remodeling via MitoKATP

Effects of CGS21680 (+CGS, $0.2 \mathrm{mg} / \mathrm{kg} / \mathrm{day}), 5 \mathrm{HD}$ (+5HD, $10 \mathrm{mg} / \mathrm{kg} / \mathrm{day})$, and Dia (+Dia, 7 $\mathrm{mg} / \mathrm{kg} /$ day) on the RV/(LV + S) (a; $\mathrm{n}=10)$, RV/BW (b; $\mathrm{n}=10), \mathrm{WT} / \mathrm{TT}(\%)(\mathrm{d} ; \mathrm{n}=10)$, and WA/TA $(\%)(e ; n=10)$ ratios in WT and A2aR-/- mice. Representative photomicrographs showing hypoxia-induced remodeling in the pulmonary arteries of the WT and A2aR-/groups exposed to hypoxia ( $10 \%$ O2) or ambient oxygen levels $(21 \%$ O2) for 4 weeks (c, $\times 400)$, the white arrow indicates the pulmonary artery. Data are presented as the mean \pm standard deviation (SD). \# $p<0.05$, \# $p<0.01$ vs normoxic group; * $p<0.05,{ }^{* *} p<0.01$ vs hypoxic group; $+p<0.05,++p<0.01$ between A2aR-/- and WT mice groups. A2aR: A2a receptors; MitoKATP: mitochondrial ATPsensitive potassium channels; 5HD, 5-hydroxydecanoic acid sodium salt; Dia, diazoxide; RV, right ventricle; LV, left ventricle; S, septum; BW, body weight; WT, wall thickness; TT, total thickness; WA, wall area; TA, total area; WT, wild-type. 

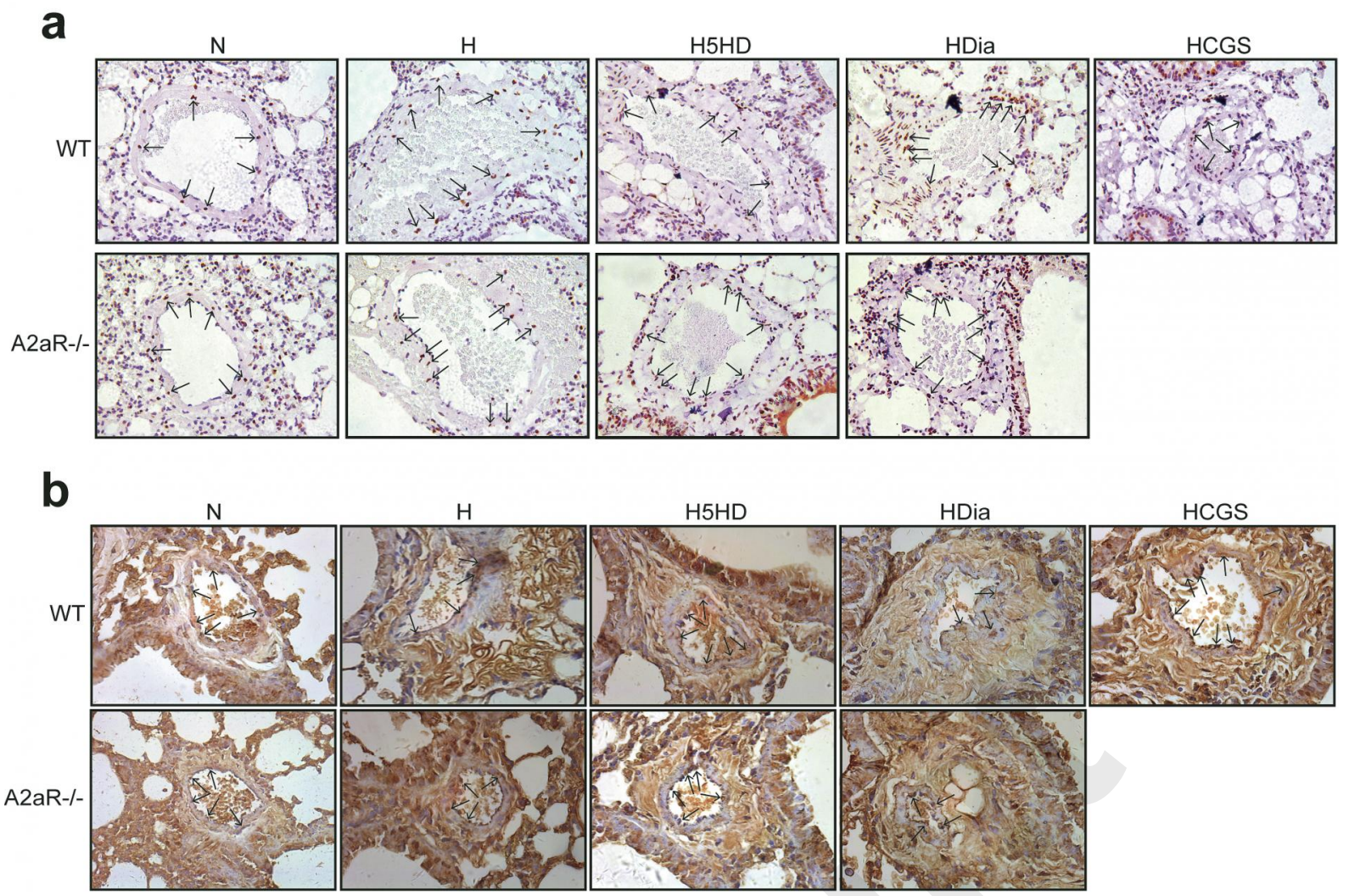

C

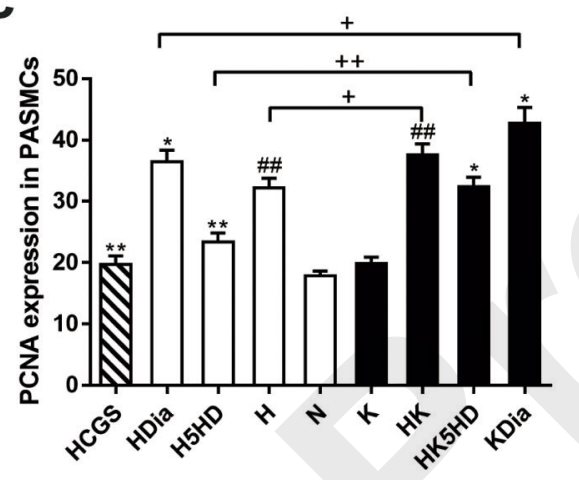

d

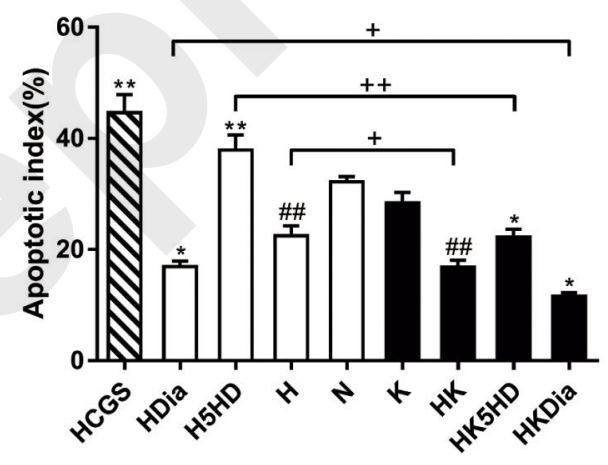

Fig. 4 A2aR alleviated hypoxia-induced excessive proliferation and apoptosis resistance in PASMCs via MitoKATP

Representative photomicrographs of PCNA (brown) expression in the pulmonary arteries of WT and A2aR-/- groups (a, $\times 400)$, the black arrow indicates the PCNA in the pulmonary arteries. Representative photomicrographs of apoptotic cells (brown) in the pulmonary arteries of WT and A2aR-/- groups ( $b, \times 400)$, the black arrow indicates the apoptotic cells in the pulmonary arteries. PCNA expression levels in PASMCs were examined by immunohistochemistry, and apoptosis levels of PASMCs were examined by TUNEL assay. Effects of CGS21680 (+CGS, $0.2 \mathrm{mg} / \mathrm{kg} / \mathrm{day}), 5 \mathrm{HD}$ (+5HD, $10 \mathrm{mg} / \mathrm{kg} / \mathrm{day}$ ), and Dia (+Dia, 7 $\mathrm{mg} / \mathrm{kg} /$ day) on PCNA expression in PASMCs (c; $n=5)$, and the apoptosis of PASMCs (d; $n$ $=5$ ) in WT and A2aR-/- mice. Data are presented as the mean \pm standard deviation (SD). \# $p<0.05$, \# $p<0.01$ vs normoxic group; ${ }^{*} p<0.05$, ${ }^{* *} p<0.01$ vs hypoxic group; $+p<$ $0.05,++p<0.01$ between A2aR-/- and WT mice groups. A2aR: A2a receptors; MitoKATP: mitochondrial ATPsensitive potassium channels; PCNA, proliferating cell nuclear antigen; WT, wild-type; PASMCs, pulmonary artery smooth muscle cells; 5HD, 5-hydroxydecanoic 
acid sodium salt; Dia, diazoxide. 
a

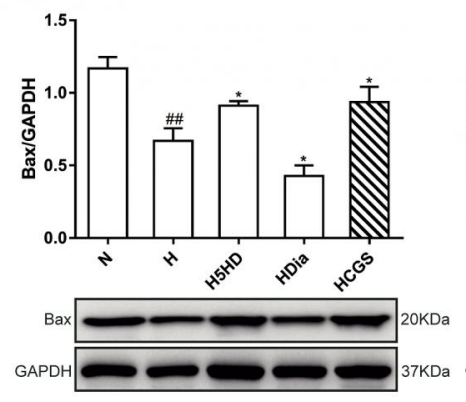

d
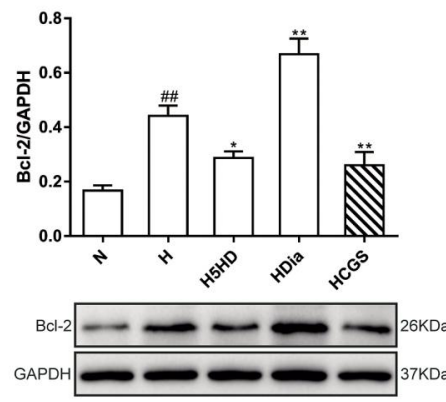

g

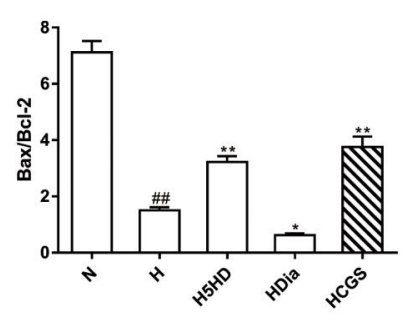

b

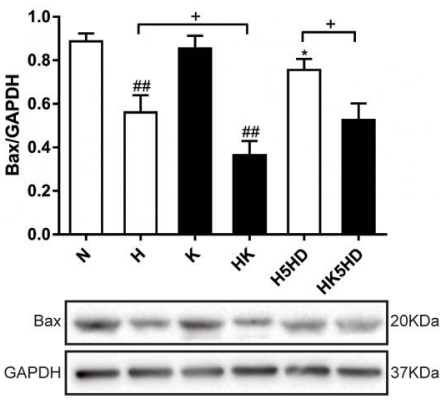

e

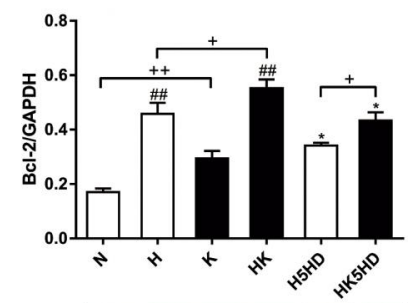

$\mathrm{BCl}-2------$

h

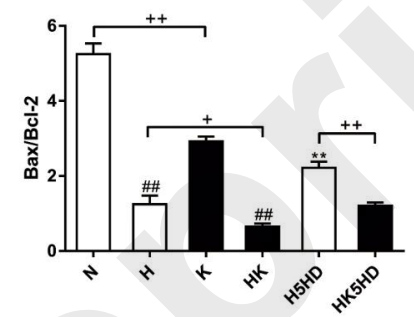

C

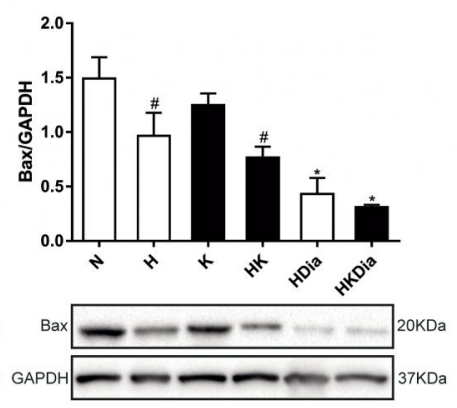

f

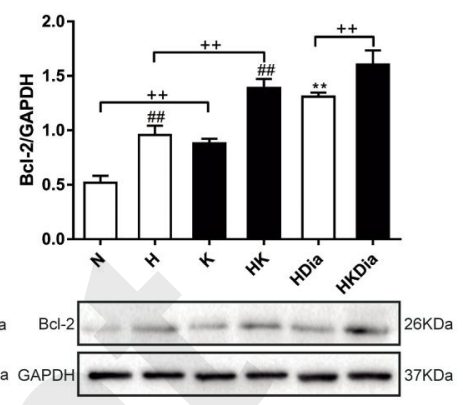

i

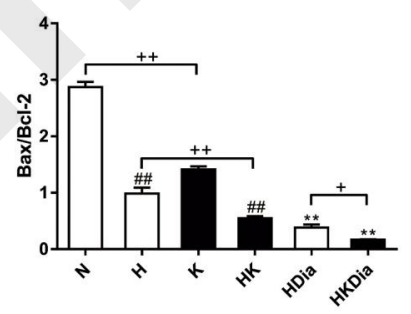

Fig. 5 A2aR alleviated hypoxia-induced apoptosis resistance in PASMCs via MitoKATP $\mathrm{Bax}$ and $\mathrm{Bcl}-2$ expression levels in lung homogenates were examined by western blotting. Effects of CGS21680 (+CGS, $0.2 \mathrm{mg} / \mathrm{kg} /$ day) on Bax and Bcl-2 expression in lung homogenates of WT mice $(a, d ; n=3)$. Effects of $5 \mathrm{HD}(+5 \mathrm{HD}, 10 \mathrm{mg} / \mathrm{kg} /$ day $)$ on Bax and $\mathrm{Bcl}-2$ expression in lung homogenates of WT and A2aR-/- mice (b, e; $n=3)$. Effects of Dia (+Dia, $7 \mathrm{mg} / \mathrm{kg} / \mathrm{day}$ ) on Bax and Bcl-2 expression in lung homogenates of WT and A2aR-/mice (c, f; $n=3$ ). Protein expression ratios of Bax to Bcl-2 were also calculated $(g, h$, and i; $\mathrm{n}=3$ ). Data are presented as the mean \pm standard deviation (SD). \# $p<0.05$, \# $p<0.01$ vs normoxic group; * $p<0.05,{ }^{* *} p<0.01$ vs hypoxic group; $+p<0.05,++p<0.01$ between A2aR-/- and WT mice groups. A2aR: A2a receptors; MitoKATP: mitochondrial ATPsensitive potassium channels; WT, wild-type; 5HD, 5-hydroxydecanoic acid sodium salt; Dia, diazoxide. 


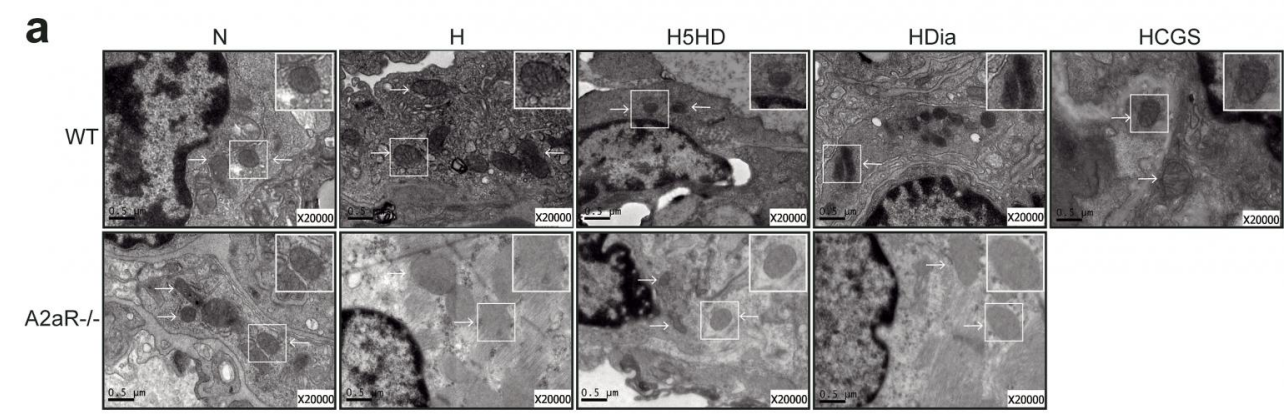

b

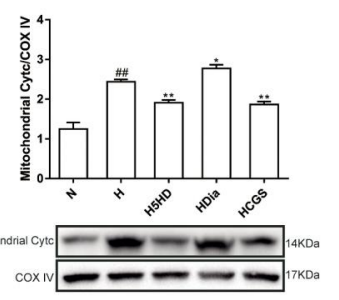

e
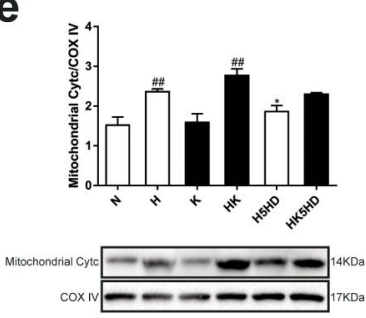

h
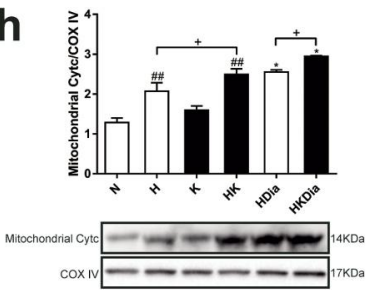

k

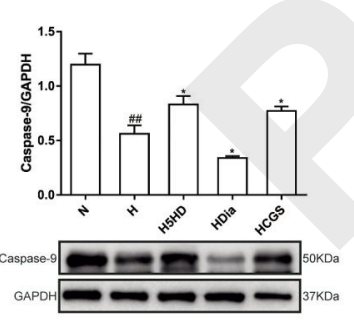

C

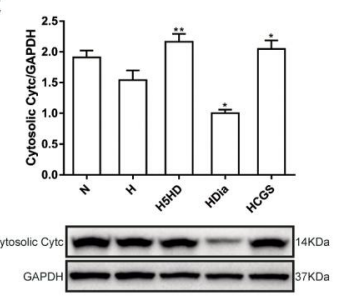

f

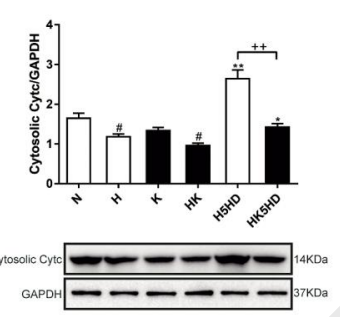

i
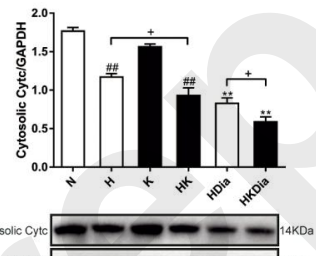

(-)-

I

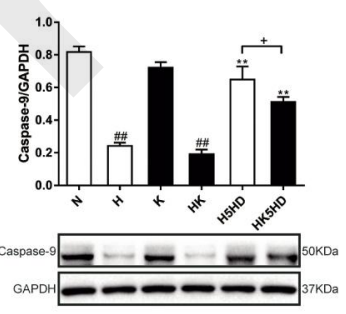

d

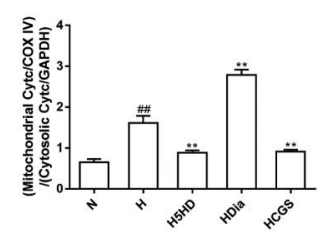

g

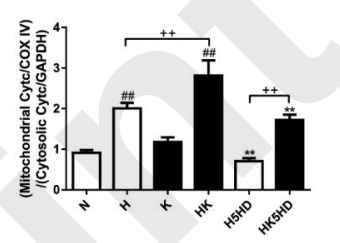

j

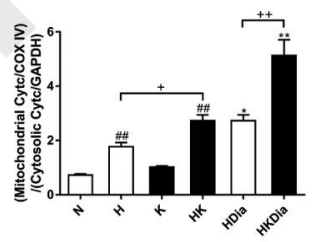

m

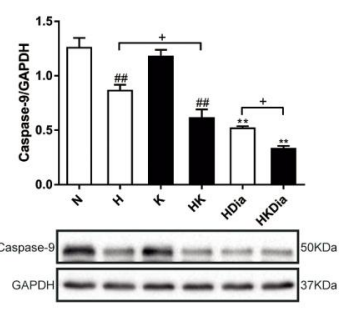

Fig. 6 A2aR modulated cell apoptosis via the mitochondrial-dependent apoptosis pathway Effects of CGS21680 (+CGS, $0.2 \mathrm{mg} / \mathrm{kg} / \mathrm{day}), 5 \mathrm{HD}$ (+5HD, $10 \mathrm{mg} / \mathrm{kg} / \mathrm{day})$, and Dia (+Dia, 7 $\mathrm{mg} / \mathrm{kg} /$ day) on $\mathrm{PH}$ at the ultrastructure level. Ultrathin sections of lung tissues from WT and A2aR-/- mice were observed by a Hitachi $\mathrm{H}-7500$ transmission electron microscopy (a, $\times 20000$ ), the white arrow indicates the mitochondria. The expression levels of cytochrome $C$ in mitochondrial and cytosol pellets and Caspase-9 in lung tissue were examined by western blotting with antibodies against cytochrome $\mathrm{C}$ with COX IV as a mitochondria marker and GAPDH as the internal control. Effects of CGS21680 (+CGS, $0.2 \mathrm{mg} / \mathrm{kg} / \mathrm{day})$ on cytochrome $\mathrm{C}$ in mitochondrial and cytosol pellets and Caspase-9 expression in lung 
homogenate of WT mice (b, c, k; $\mathrm{n}=3$ ). Effects of 5HD (+5HD, $10 \mathrm{mg} / \mathrm{kg} / \mathrm{day})$ on cytochrome $\mathrm{C}$ in mitochondrial and cytosol pellets and Caspase-9 expression in lung homogenate of WT mice (e, $\mathrm{f}, \mathrm{l} ; \mathrm{n}=3$ ). Effects of Dia (+Dia, $7 \mathrm{mg} / \mathrm{kg} /$ day) on cytochrome C in mitochondrial and cytosol pellets and Caspase- 9 expression in lung homogenate of WT mice $(h, i, m ; n=3)$. Protein expression ratios of cytochrome $C$ in mitochondrial and cytosol pellets were also calculated $(\mathrm{d}, \mathrm{g}, \mathrm{j} ; \mathrm{n}=3)$. Data are presented as the mean \pm standard deviation (SD). \# $p<0.05$, \# $p<0.01$ vs normoxic group; ${ }^{*} p<0.05$, ${ }^{* *} p<0.01$ vs hypoxic group; $+p<0.05,++p<0.01$ between A2aR-/- and WT mice groups. A2aR: A2a receptors; $5 \mathrm{HD}, 5$-hydroxydecanoic acid sodium salt; Dia, diazoxide; $\mathrm{PH}$, pulmonary hypertension; WT, wild-type. 


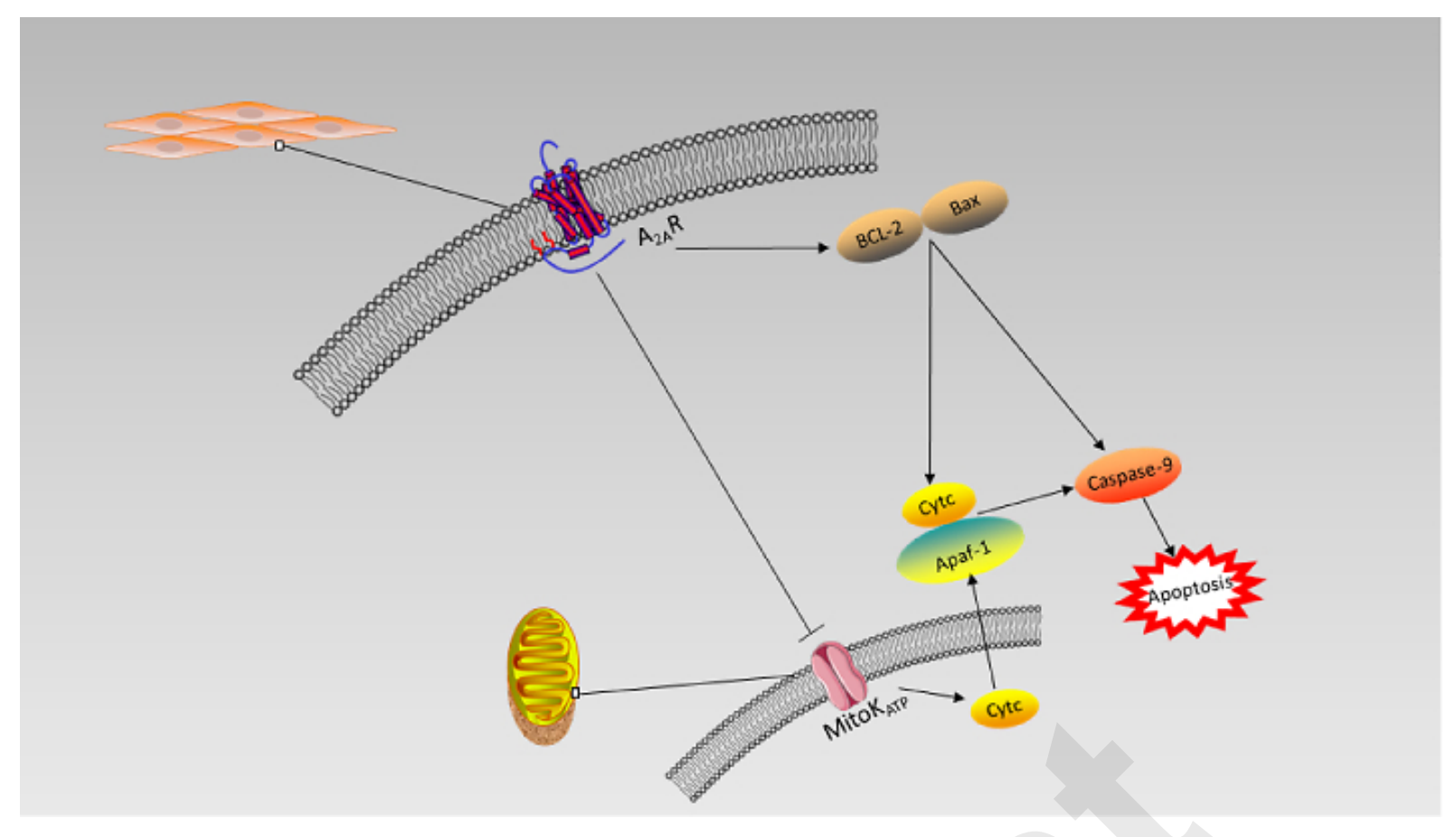

Fig. 7 A2aR attenuated HPH via MitoKATP

A2aR attenuated HPH by modulating the mitochondrial-dependent apoptosis pathway via MitoKATP. HPH, hypoxia-induced pulmonary hypertension. 